\title{
Combinação de Classificadores para Reconhecimento de Padrões
}

\author{
PAULO SÉRGIO PRAMPERO
}

OṘENTADOR: PROF. DR. ANDRÉ CARLOS PONCE

DE LEON FERREIRA DE CARVALHO

Dissertação apresentada ao Instituto de Ciências Matemáticas de São Carlos, da Universidade de São Paulo, como parte dos requisitos necessários para obtenção do título de "Mestre em Ciências de Computação $e$ Matemática Computacional".

São Carlos

- 1998- 
PARA A MINHA AMADA ESPOSA, ALESSANDRA CRISTINA PELICER.

PARA MEU PRIMEIRO FILHO, PEDRO PELICER PRAMPERO, QUE AINDA NÃO NASCEU, E PARA SEUS FUTUROS IRMÃOS E IRMÃS. 


\section{AGRADECIMENTOS}

A DEUS, inteligência suprema que nos impulsiona para a evolução, por colocar pessoas tão boas e generosas em meu caminho, por dar me a vida e uma infinidade de oportunidades.

Ao Professor André pelo exemplo de vida, de amor ao próximo e de cientista. Por me ensinar a ter amor no que se faz, e por me ajudar sempre, nos feriados, nos finais de semanas, em qualquer tempo sua dedicação foi incansável.

Ao Allan Kardec, por frases como essa: 'Nascer, viver, morrer, renascer ainda e progredir sempre, tal é a Lei”, que me estimula a evoluir.

Aos meus Pais, José Prampero e Jorcelina de Carvalho Prampero, que sempre me ajudaram em qualquer tempo, que me deram ótimos exemplos de vida e de doação ao próximo Agradeço-lhes do fundo do meu coração por serem mais maravilhosos do que jamais sonhei.

Aos meus irmãos, José Eduardo, André Luis, Luis Fernando e Anna Carolina, por serem meus anjos da guarda. Pela amizade leal, pela mão mais do que amiga em todas as horas. Por serem espiritos iluminados que me ensinam e ajudam sempre.

A mãe da minha esposa, D. Olga. pela amizade, pelo desprendimento das "coisas" terrenas e pela ajuda constante.

Ao amigo Estéfane, por estar presente nos trabalhos em grupo, por estar sempre disposto a ajudar e por sua lista, que a toda segunda-feira me fazia sentir melhor.

A Professora Carolina e ao Professor Mascarenhas, pelos bons conselhos e pelas criticas construtivas, que sem dúvida alguma ajudaram muito este trabalho

A todos os Professores que me ajudaram ministrando disciplinas, dando conselhos, ou que de algum modo colaboraram durante meus estudos realizados neste instituto.

Aos senhores que guardam este instituto durante à noite, pela amizade e pelas conversas que me faziam sentir-se em casa, nas noites no ICMSC

As bibliotecárias, que com simpatia sempre me ajudaram.

As secretárias da pós-graduação, pela ajuda, competência e dedicação ao trabalho.

Aos amigos do LABIC, que transformaram horas de trabalho em horas de lazer e diversão

Ao CNPQ pelo apoio financeiro fornecido durante o desenvolvimento deste trabalho 


\section{RESUMO}

PRAMPERO, P. S. (1998). Combinação de Classificadores para Reconhecimento de Padrões. São Carlos, 1998. Dissertação (Mestrado) - Instituto de Ciências Matemáticas de São Carlos, Universidade de São Paulo.

O cérebro humano é formado por um conjunto de neurônios de diferentes tipos, cada um com sua especialidade. A combinação destes diferentes tipos de neurônios é um dos aspectos responsáveis pelo desempenho apresentado pelo cérebro na realização de várias tarefas.

Redes Neurais Artificiais são técnicas computacionais que apresentam um modelo matemático inspirado no sistema nervoso e que adquirem conhecimento através da experiência.

Uma alternativa para melhorar o desempenho das Redes Neurais Artificiais é a utilização de técnicas de Combinação de Classificadores. Estas técnicas de combinação exploram as diferenças e as semelhanças das redes para a obtenção de resultados melhores.

Dentre as principais aplicações de Redes Neurais Artificiais está o Reconhecimento de Padrões. Neste trabalho, foram utilizadas técnicas de Combinação de Classificadores para a combinação de Redes Neurais Artificiais em problemas de Reconhecimento de Padrões.

Palavras-chave: Reconhecimento de Padrões, Redes Neurais Artificiais, Combinação de Classificadores. 


\section{ABSTRACT}

PRAMPERO, P. S. (1998). Combinação de Classificadores para Reconhecimento de Padrões. São Carlos, 1998. Dissertation (Mastership) - Institute of Mathematics Science of São Carlos, University of São Paulo.

The human brain is formed by neurons of different types, each one with its own speciality. The combination of theses different types of neurons is one of the main features responsible for the brain performance in several tasks.

Artificial Neural Networks are computation technics whose mathematical model is based on the nervous system and learns new knowledge by experience.

An alternative to improve the performance of Artificial Neural Networks is the employment of Classifiers Combination techniques. These techniques of combination explore the difference and the similarity of the networks to achieve better performance.

The main application of Artificial Neural Networks is Pattern Recognition. In this work, Classifiers Combination techniques were utilized to combine Artificial Neural Networks to solve Pattern Recognition problems.

Keywords: Pattern Recognition, Artificial Neural Networks, Classifiers Combination. 


\section{ÍNDICE ANALÍTICO}

1 - Introdução

1.1 - CONTEXTO 1

1.2 - MÓDULO DE COMBINAÇĀO. 3

1.3 - ORGANIZAÇÄO DO TRABALHO 3

\section{2 - Reconhecimento de Padrões}

2.1 - INTRODUÇÃO 4

2.2 - RECONHECIMENTO DE PADRŌES. .4

2.3 - ABORDAGENS EM RECONHECIMENTO DE PADRÕES 6

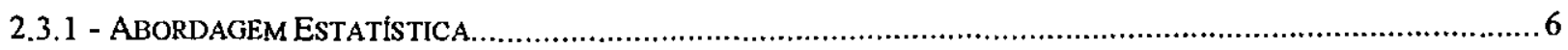

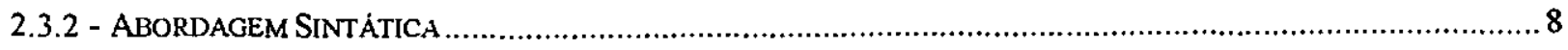

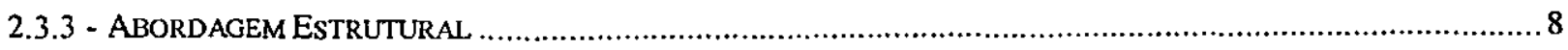

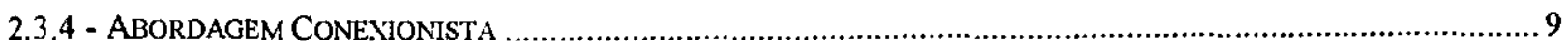

2.4 - ESTRUTURA TÍPICA DE UM SISTEMA DE RECONHECIMENTO DE PADRÕES ...........................9

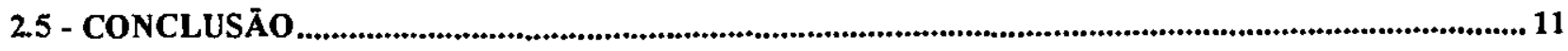

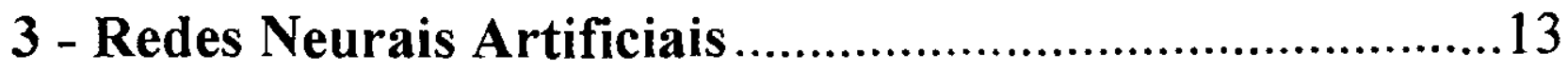

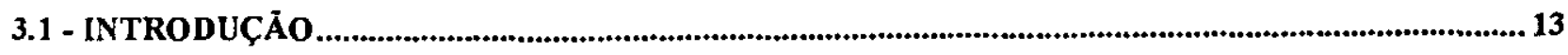

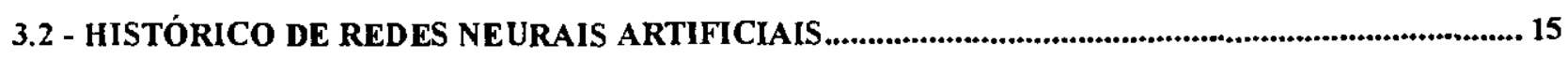

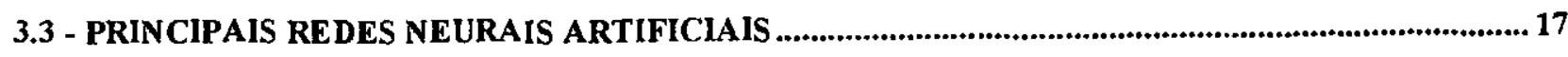


3.3.1 - PERCEPTRON MULTICAMADAS

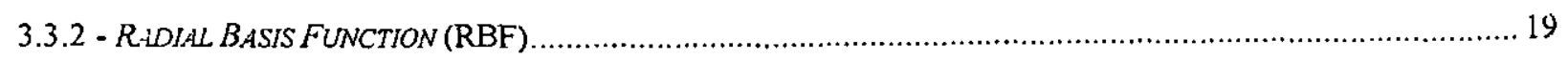

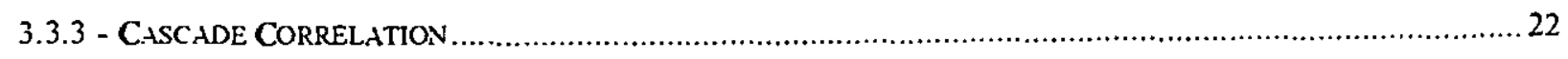

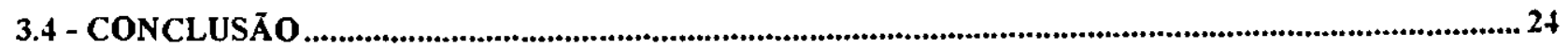

4 - Reconhecimento de Alvos .......................................26

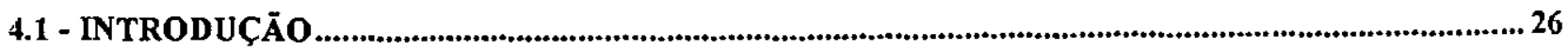

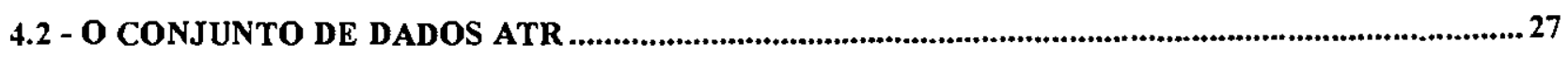

4.3 - PRÉ-PROCESSAMENTO E SEGMENTAÇÃO ............................................................................. 29

4.4 - EXTRAÇÃO E SELEÇÃO DE CARACTERÍSTICAS ..........................................................................30

4.5 - CLASSIFICAÇÃO

4.6 - UM EXEMPLO DE RECONHECIMENTO E CLASSIFICAÇÃO DE IMAGENS ................................... 32

+.7 - CONCLUSÄO

5 - Combinação de Classificadores..................................35

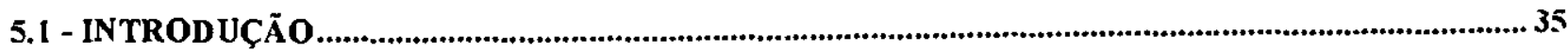

5.2 - VANTAGENS E DESVANTAGENS DA COMBINAÇÃO DE CLASSIFICADORES...............................36

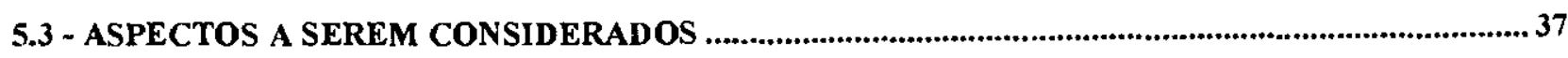

5.4 - NÍVEIS DE COMBINAÇÃO DE CLASSIFICADORES .......................................................................39

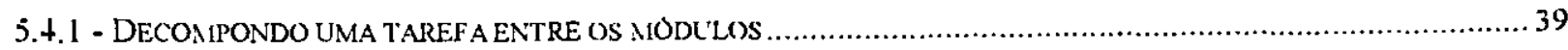

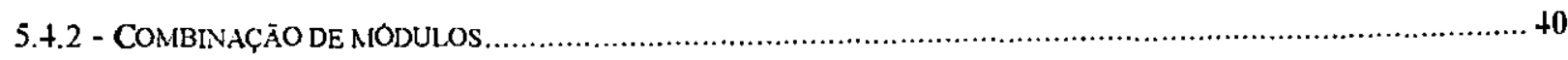

5.5 - COMBINAÇĀO DOS CLASSIFICADORES EM PARALELO ...........................................................1

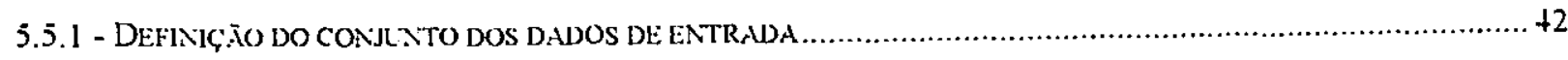


5.5.1.1 - Um único conjunto de entrada 42

5.5.1.2 - Particionando o conjunto original em subconjuntos de amostras ........................................... 43

5.5 .2 - COMBINAÇন̃O DAS SAID.AS DOS CLASSIFICADORES COMBINADOS EM PARALELO.......................................4

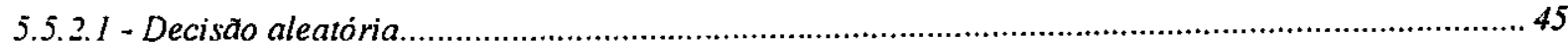

5.5 .2 .2 - Decisão pela Combinação linear das saidas .........................................................................45

5.5.2.3 - Decisão pela Combinação não linear das saídas...................................................................... 46

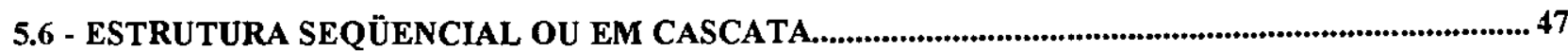

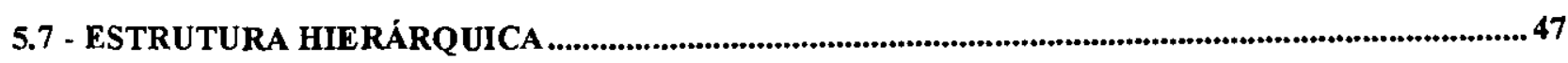

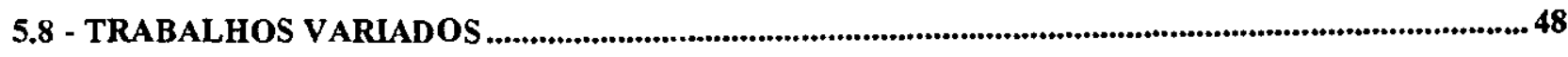

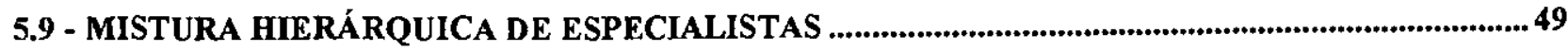

5.9 .1 - ALGORITMO DE TREINAMENTO PARA A ARQUITETURA HME .....................................................52

5.10 - MÉTODO DE COMBINAÇÃO PROPOSTO

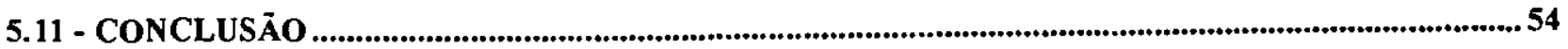

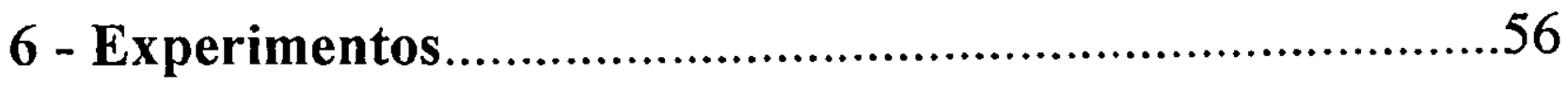

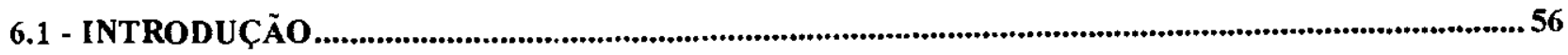

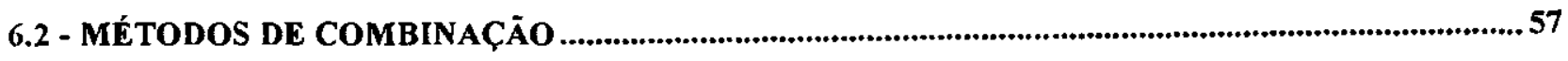

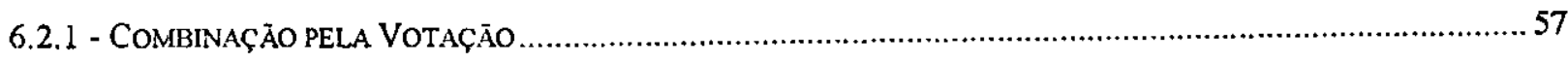

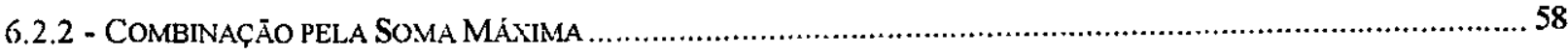

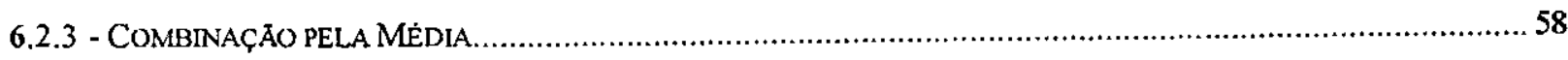

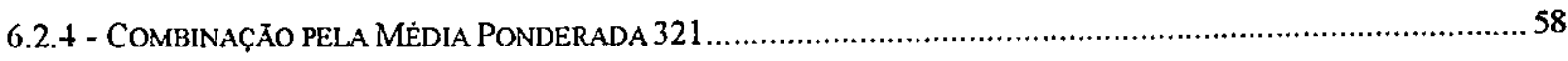

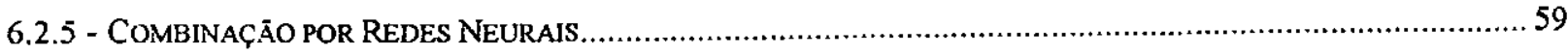

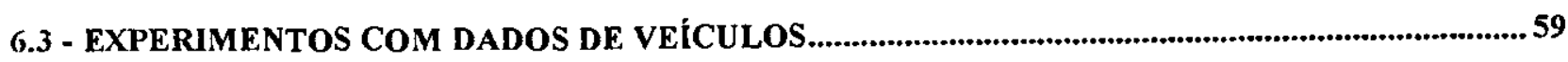

6.4 - EXPERIMENTOS COM DADOS DA MARINHA AMERICANA .................................................65

6.5 - EXPERIMENTOS COM DADOS DA MARINHA BRASILEIRA......................................................69 


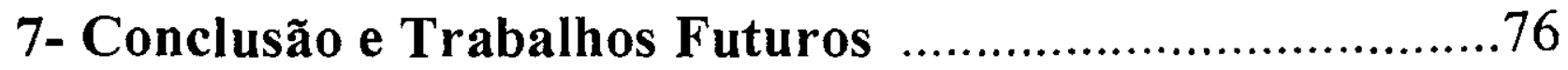

7.1 - CONCLUSÃO .76

7.2 - TRABALHOS FUTUROS .77

8 - Referências Bibliográficas 


\section{LISTA DE FIGURAS}

FIGURA 2.1 - ESTRUTURA SIMPLIFICADA DO RECONHECIMENTO DE PADRŐES. ..............................6

FIGURA 2.2 - EXEMPLO DE UM SISTEMA NEURAL DE RECONHECIMENTO DE PADRŐES. ................. 11

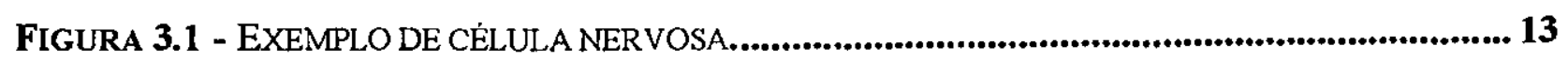

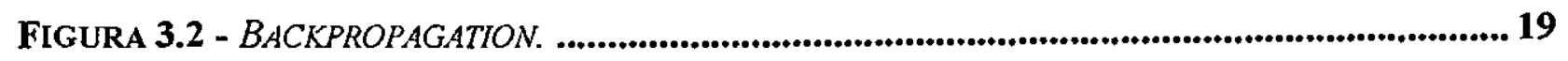

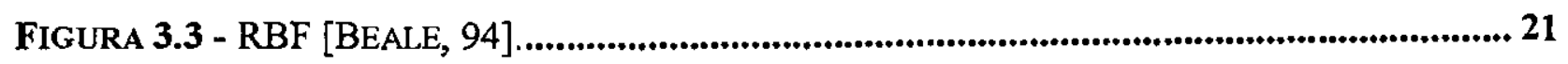

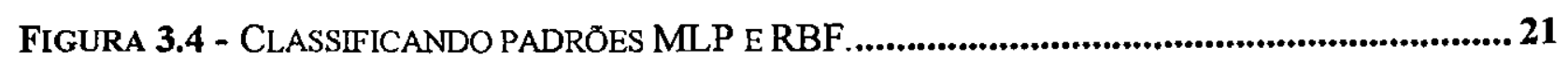

FIGURA 3.5 - CASCADE CORRELATION NO FORMATO INICIAL................................................... 23

Figura 3.6 - CASCADE CORRELATION DEPOIS DA SEGUNDA UNIDADE ESCONDIDA ADICIONADA. 24

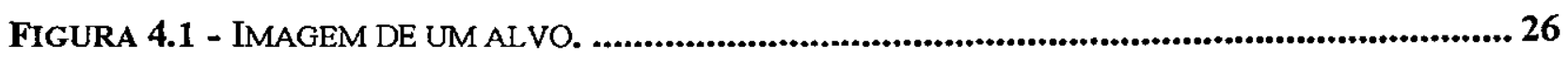

FIGURA 4.2 - VISÃO GERAL DO RECONHECIMENTO AUTOMÁTICO DE ALVOS. ................................ 27

FIGURA 4.3 - EXEMPLO DO PROCESSAMENTO DAS IMAGENS. ........................................................ 32

FIGURA 4.4 - UM EXEMPLO DE UM SISTEMA DE RECONHECIMENTO DE ALVOS................................ 33

FIGURA 5.1 - SISTEMA SIMPLIFICADO DE UM CLASSIFICADOR. .................................................36

FIGURA 5.2 - ESTRUTURA DE COMBINAÇÃO DO MODELO EM PARALELO.........................................4 42

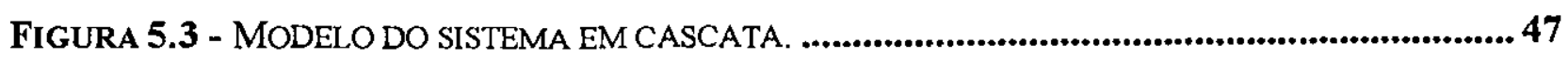

FIGURA 5.4 - MODELO DO SISTEMA HIERÁRQUICO. .................................................................... 48

FIGURA 5.5 - MISTURA HIERÁRQUICA DE ESPECIALISTA EM DOIS NIVEIS......................................50

FIGURA 5.6 - DIVISÃO DO CONJUNTO DE DADOS NO SISTEMA HME. ............................................ 51 


\section{DE TABELAS}

TABELA 1.1 - OS INSTITUTOS E SUAS RESPECTIVAS TAREFAS. ......................................................... 1

TABELA 6.1 - RESULTADO DA REDE CASC.ADE CORRELATION ...................................................60

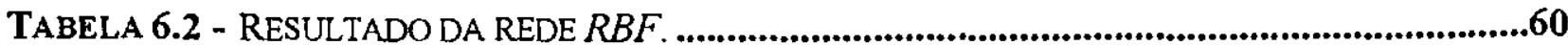

TABELA 6.3 - RESULTADO DA REDE MLP............................................................................61

TABELA 6.4 - RESULTADO DO MÉTODO COMBINAÇÃO PELA VOTAÇÃO. .......................................61

TABELA 6.5 - RESULTADO DO MÉTODO COMBINAÇÃo PELA SOMA MÁXIMA. ..............................62

TABELA 6.6 - RESULTADO DO MÉTODO COMBINAÇÃO PELA MÉDIA. .........................................62

TABELA 6.7 - RESUL TADO DO MÉTODO DE COMBINAÇÃO PELA MÉDIA PONDERADA 321............63

TABELA 6.8 - RESULTADO DO MÉTODO DE COMBINAÇÃO PELA REDE MLP . ................................63

TABELA 6.9 - RESULTADO DO MÉTODO DE COMBINAÇÃO PELA REDE RBF , ..................................64

TABELA 6.10 - COMPARAÇÃO ENTRE O DESEMPENHO DOS MĖTODOS DE COMBINAÇÃO NA FASE DE TESTE............64

TABELA 6.11 - RESULTADO DA REDE CASCADE CORRELATION ................................................65

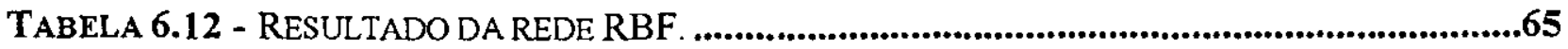

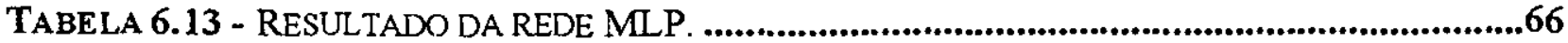

TABELA 6.14 - RESUL TADO DO MÉTODO DE COMBINAÇÃO PELA VOTAÇÃO...................................66

TABELA 6.15 - RESULTADO DO MÉTODO DE COMBINAÇÃO SOMA MÁXIMA. .................................67

TABELA 6.16 - RESULTADO DO MÉTODO DE COMBINAÇÃO PELA MÉDIA. .....................................67

TABEla 6.17 - RESULTADO DO MÉTODO DE COMBINAÇÃO PELA MÉdIA PONDERADA 321..........67

TABELA 6.18 - RESULTADO DO MÉTODO DE COMBINAÇÃO PELA REDE MLP..................................68

TABELA 6.19 - RESULTADO DO MÉTODO DE COMBINAÇÃO PELA REDE RBF. ...............................68

TABELA 6.20 - COMPARAÇÃO ENTRE O DESEMPENHO DOS MÉTODOS DE COMBINAÇÃO NA FASE DE TESTE. ...........69

TABELA 6.21 - RESULTADO DA REDE C.ASC.ADE CORRELATTION ....................................................70

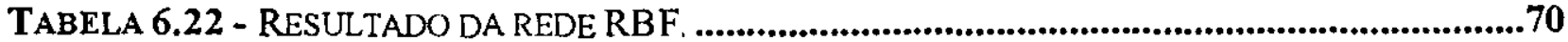

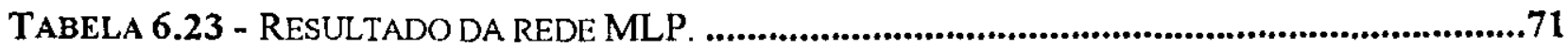

TABELA 6.24 - RESULTADO DO MÉTODO DE COMBINAÇÃO PELA VOTAÇÃO..................................71

TABELA 6.25 - RESULTADO DO MÉTODO DE COMBINAÇÃO SOMA MÁXIMA. .................................72

TABELA 6.26 - RESULTADO DO MÉTODO DE COMBINAÇÃO PELA MÉDIA. ....................................72 
TABELA 6.27 - RESULTADO DO MÉTODO DE COMBINAÇÃO PELA MÉDIA PONDERADA 321...........72

TABELA 6.28 - RESULTADO DO MÉTODO DE COMBINAÇÃO PELA REDE MLP................................73

TABELA 6.29 - RESULTADO DO MÉTODO DE COMBINAÇÃO PELA REDE RBF. ...............................73

TABELA 6.30 - COMPARAÇĀO ENTRE O DESEMPENHO DOS MÉTODOS DE COMBINAÇÅO NA FASE DE TESTE. ...........74 


\section{INTRODUÇÃO}

\section{1 - Contexto}

Este projeto diz respeito à combinaçāo de classificadores para reconhecimento de imagens de navios provenientes de radar. Este trabalho faz parte de um projeto temático CNPQ/PROTEM, o projeto SAPRI (Sistema de Aquisição, Processamento e Reconhecimento de Imagens). O objetivo do projeto SAPRI é o de desenvolver um ambiente voltado para a segurança da navegação e para o controle de tráfego aeronaval. Este projeto teve início em janeiro de 1997 e está sendo desenvolvido pelas instituiçōes: Instituto de Pesquisas da Marinha do Brasil, Instituto de Computação da UNICAMP, Laboratório de Computação Inteligente da UFPE, Laboratório de Inteligência Computacional do ICMSC/USP - São Carlos, Grupo Pirineus da Escola de Engenharia Elétrica da UFG e o Instituto de Informática da UFRGS. Os institutos e suas respectivas tarefas estão apresentados na Tabela 1.1.

\begin{tabular}{|c|c|}
\hline Instituto & Tarefa atribuída \\
\hline Marinha do Brasil & Captura de Imagens através de Radar. \\
\hline UNICAMP & Pré-processamento de Imagens, eliminação de ruído. \\
\hline UFPE & Extração de características de imagens e Reconhecimento de \\
& Padrōes. \\
\hline ICMSC - USP & Classificação e Reconhecimento de Padrões. \\
\hline UFG & Reconhecimento de Padrões. \\
\hline UFRGS & Análise tática. \\
\hline
\end{tabular}

Tabela 1.1 - Os institutos e suas respectivas tarefas. 
No tocante ao aspecto tecnológico, o projeto visa à elaboração de um ambiente computacional eficiente, que integre todas as fases envolvidas no processamento automatizado de imagens de radar, desde a fase inicial de aquisição de imagens até o processo final de tomada de decisões. O sistema beneficiará em grande parte à Marinha do Brasil, que utilizará o sistema no aparelhamento de suas embarcações.

Um dos benefícios desse sistema consiste em tomar o processo de monitoramento do ambiente menos dependente da experiência, sensibilidade $\theta$ do nível de atenção dos operadores humanos, os quais são suscetiveis a flutuações decorrentes dos estados de cansaço e stress.

É importante salientar que embora a motivação inicial para este trabalho tenha sido gerada pela necessidade de um sistema para a Marinha do Brasil, a tecnologia $\theta$ os resultados científicos gerados com o mesmo, também apresentam um grande valor potencial para outros setores da indústria nacional que se utilizem de sistemas de processamento de imagens $\theta$ classificação de padrões.

Concluído o trabalho, a tecnologia desenvolvida será integralmente aproveitada pela Marinha do Brasil, refletindo-se em um avançado sistema de controle tático a ser implantado em embarcações que sofram atualizações técnicas. A longo prazo, através do crescimento da interação, por decorrência do esquema de compartilhamento de responsabilidades entre os participantes do projeto, um dos mais valiosos resultados a ser colhido será a projeção, em instituiçōes acadêmicas, de pesquisas aplicadas à área de defesa, atividade atualmente restrita às instituições militares.

O módulo a ser desenvolvido no Instituto de Ciências Matemáticas de São Carlos ICMSC/USP é a combinação de modelos de Redes Neurais e utilização de redes construtivas para o Reconhecimento de Padrões. As pesquisas a serem desenvolvidas para a execução deste módulo envolveram estudos principalmente nas áreas de Redes Neurais Artificiais, Reconhecimento de Padrōes e Combinação de Classificadores.

O Módulo de Reconhecimento de Padrōes é responsável pela análise da adequação de modelos através da investigação de diversas abordagens aplicadas em reconhecimento de imagens de radar e de técnicas de combinação destes modelos visando uma melhor performance do sistema. 


\section{2 - Módulo de Combinação}

Para a realização do módulo de combinação de classificadores vários métodos de combinação foram implementados. Três redes foram utilizadas pelos métodos de combinação: (Multi Layer Perceptron, Radial Basis Function e Cascade Correlation).

O módulo de combinação compara o desempenho de diversos métodos de combinação de classificadores, utilizando três bases de dados: Base de dados de imagens da Marinha Americana, Base de dados de Silhuetas de Veículos e a da Marinha do Brasil. Uma vantagem de utilizar outras bases de dados, além da fornecida pela Marinha do Brasil, é a possibilidade de analisar o desempenho do sistema de combinação de uma forma mais genérica.

\section{3 - Organização do Trabalho}

Quanto à organização deste trabalho, o capítulo 2 apresenta uma breve introdução ao Reconhecimento de Padrões. Neste capitulo é apresentado a estrutura típica de um sistema de Reconhecimento de Padrões. Além disso, ele descreve as abordagens estatística, sintática, estrutural e conexionista.

O capítulo 3 contém um histórico das Redes Neurais. No final do capítulo estão descritas as Redes Neurais utilizadas na combinação de classificadores deste trabalho.

No capítulo 4 é discutido um sistema típico de Reconhecimento de Alvos incluindo as fases desse sistema, desde a aquisição do conjunto de dados até a fase de classificação.

No capitulo 5 são apresentados métodos de Combinação de Classificadores, com as vantagens e desvantagens de cada um deles. No capitulo 6 são apresentados os resultados de experimentos realizados com os classificadores individuais e os diferentes métodos de combinação. Os resultados foram obtidos utilizando as três bases de dados já mencionadas. No capítulo 7 são apresentadas as conclusões $e$ propostas para trabalhos futuros. Por fim, no capitulo 8 é apresentado a Bibliografia da dissertação. 


\section{RECONHECIMENTO DE PADRŌES}

\section{1 - Introdução}

O Reconhecimento de Padrões é uma tarefa habitualmente realizada no dia a dia das pessoas. Quando uma criança de tenra idade começa a chorar e sua mãe pega-a em seu colo, ela para de chorar pois realizou um reconhecimento de padrões (verificou que se trata da sua mãe). A criança, reconhecendo sua mãe, acabou de realizar uma tarefa simples para os seres humanos, mas complicada para os computadores.

"Re-conhecer" significa, primeiro gerar "conhecimento" a partir de dados, e depois, "re-identificar" dados já conhecidos. Para realizar estas tarefas, os pesquisadores da área de reconhecimento de padrões pesquisam diferentes técnicas.

Espera-se que um dia os computadores reconheçam imagens, vozes e sinais diversos tão bem quanto os seres humanos. Esta busca por técnicas eficientes de reconhecimento de padrōes está motivada nas inúmeras aplicações deste sistema.

As técnicas descobertas podem ser agrupadas de acordo com a abordagem utilizada. Neste capítulo, logo após uma definição de Reconhecimento de Padrões, serão descritas suas principais abordagens.

\section{2 - Reconhecimento de Padrões}

Reconhecimento de Padrōes é a ciência que compreende a identificação ou classificação de medidas de informação em categorias. Estas categorias têm a característica de representar entidades ou padrões de informação que apresentam similaridades. Reconhecimento de padrões é composto de um conjunto de técnicas e 
abordagens que são usadas de forma integrada na solução de diversos problemas práticos [Vasconcelos, 95].

Reconhecimento de padrōes está direcionado para a tomada de decisão sobre padrões complexos de informações. Um dos objetivos é automatizar tarefas realizadas pelos seres humanos. Exemplos destas tarefas são: reconhecer o rosto de um amigo, decidir o próximo movimento em um jogo de xadrez, ou definir quando gastar o dinheiro da poupança. Existem várias aplicações onde a técnica de reconhecimento de padrões tem sido aplicada:

1. Processamento e análise de sinais;

2. Reconhecimento de Voz, de Face, de Caracteres;

3. Classificação de Identificação de Impressões digitais.

As informaçōes disponíveis sobre os padrões exercem forte influência sobre a técnica escolhida. Para problemas que possuem um conjunto de padrōes pertencentes a classes pré-definidas que podem ser representados por um conjunto de sinais de entrada para o classificador, a tarefa do sistema é classificar um padrão desconhecido em uma das classes disponíveis. Esta tarefa é chamada de classificação ou reconhecimento de padrões supervisionado.

No caso de não existirem classes pré-definidas, o sistema deve, em primeiro lugar, determinar as classes baseado nos dados disponiveis. Depois o sistema agrupa os padrões nestas classes. Neste sistema, quando um padrão desconhecido é apresentado para a definição de uma função discriminante, verifica-se a similaridade deste padrão com as classes existentes, para decidir se inclui o novo padrão em uma classe existente ou cria uma nova classe para este padrão. Esta forma de reconhecimento de padrões é chamada analise de cluster ou reconhecimento de padrões não supervisionado.

A analise cluster tem sido muito aplicada no campo de reconhecimento de padrões, principalmente no reconhecimento de padrões estatísticos. No reconhecimento estatístico muito pouco é assumido sobre as classes de padrões, todas as informações são aprendidas com os padrões de entrada [Ripley, 96].

Conforme apresentado na Figura 2.1, um sistema de Reconhecimento de Padrōes pode ser considerado como um dispositivo de dois estágios. O primeiro estágio é a extração de características. O segundo é responsável pela classificação. As 
características extraídas são medidas extraídas do padrão de entrada que podem classificá-lo corretamente [Beale, 94].

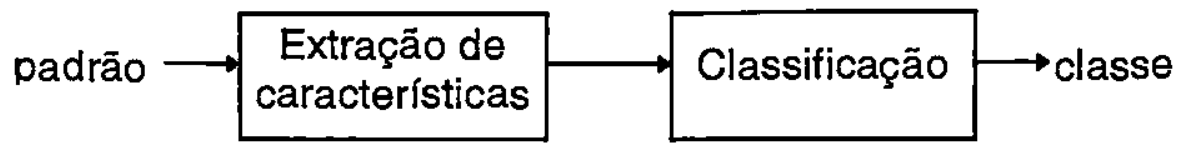

Figura 2.1 - Estrutura simplificada do Reconhecimento de Padrões.

Existem várias técnicas para o reconhecimento de padrões. Estas técnicas estão agrupadas em abordagens. A seguir serão descritas as principais abordagens utilizadas para o Reconhecimento de Padrões.

\section{3 - Abordagens em Reconhecimento de Padrões}

As principais técnicas para o reconhecimento de padrões podem ser classificadas em quatro abordagens: estatística, sintática, estrutural e conexionista. Estas abordagens são descritas nas subseções a seguir.

\subsection{1 - Abordagem Estatística}

A mais antiga das abordagens, pode ser dividida em abordagem estatística com aprendizado não supervisionado e com aprendizado supervisionado.

$\mathrm{Na}$ abordagem estatística com aprendizado não supervisionado, cada padrão de treinamento pode ser uma classe diferente ou todo o conjunto de treinamento pode pertencer a mesma classe. Para resolver este problema, no inicio do processo de aprendizagem, para o primeiro padrão, supõe-se a existência de uma classe (centro) de classificação. Esta classe (centro) é um padrão que foi eleito para representar uma classe.

Depois da suposição, começa o cálculo da função de erro utilizando um segundo padrão do conjunto de treinamento. Se o resultado da função erro para um novo padrão não for aceitável, então cria-se uma nova classe para este padrão. Se o resultado for aceitável, então o segundo padrão é agrupado ao primeiro formando uma classe com dois representantes. Este processo é realizado para todos os padrões do 
conjunto de treinamento, até que os resultados da função erro sejam aceitáveis para todos os padröes.

O resultado do algoritmo é um ou mais agrupamentos (classes) de padrōes. Este processo de aprendizagem, descrito sucintamente, é apenas uma técnica de aprendizado não supervisionado de classificadores estatísticos. Um exemplo de um classificador estatístico não supervisionado é o algoritmo $C$-means clustering, que possui pequenas variações do algoritmo $K$-means clustering [Rauber, 97]. O problema da aprendizagem não supervisionada é que o sistema pode fornecer um número de classes muito diferente do número ótimo, criando classes que não deveriam ser criadas ou não criando classes que deveriam ser criadas.

$\mathrm{Na}$ abordagem estatística supervisionada, para classificar um padrão é feita uma comparação entre as suas características e características correspondentes associadas a cada uma das classes. O padrão é classificado como pertencente à classe mais semelhante. A grande desvantagem dessa abordagem é que suposições teóricas são geralmente assumidas a priori a respeito da estrutura de distribuição das classes de padrões, algumas dificilmente observadas na prática [Vasconcelos, 95].

A abordagem estatística supervisionada possui dois principais grupos de métodos, os métodos paramétricos e os não paramétricos. A seguir será descrito cada um destes métodos.

\section{Métodos paramétricos}

Nos métodos paramétricos, um modelo de distribuição dos dados é assumido de antemão. Este modelo apresenta um número de parâmetros que são otimizados pelo próprio modelo em função do conjunto de dados. A desvantagem deste método é que a função de densidade paramétrica escolhida pode ser incapaz de fornecer uma boa representação para a verdadeira função de densidade do conjunto de dados [Bishop,96].

O modelo paramétrico mais utilizado é a distribuição Gaussiana, a qual tem um número conveniente de propriedades analíticas e estatísticas. Existem várias técnicas para determinar os parãmetros do modelo de distribuição paramétricos. As mais conhecidas são: Probabilidade Máxima e Inferēncia Bayesiana. 


\section{Métodos não paramétricos}

Ao contrário do método anterior, no método não paramétrico nenhum modelo de distribuição de dados é assumido anteriormente. O modelo é inteiramente determinado pelo conjunto de dados. O problema deste método é que o número de parâmetros cresce com o tamanho do conjunto de dados, assim o modelo pode rapidamente tornar-se difícil de manejar [Bishop, 96].

As técnicas mais conhecidas dos métodos não paramétricos são: $O$ método de Historiogramas (este método tem uma importante ligação com a rede RBF) e a técnica dos $\mathrm{K}$ vizinhos mais próximos [Bishop,96].

\subsection{2 - Abordagem Sintática}

Baseado em linguagens formais, este enfoque trata o problema de reconhecimento em termos sintáticos, procurando fazer uma analogia entre a estrutura do padrão e a sintaxe de uma linguagem. O padrão é decomposto em primitivas, as quais têm suas relações estudadas e os resultados usados para gerar uma descrição do padrão. A decisão é feita por um interpretador. O modelo é capaz de lidar com padrões de grande complexidade.

Um exemplo de reconhecimento de padrões sintático é o de relacionar a estrutura de padrōes com a sintaxe de uma linguagem definida formalmente. Na própria definição da linguagem fica determinada de forma embutida a geração de padrões (representação) e análise dos mesmos (identificação) [Vasconcelos, 95]. Um compilador é um exemplo de um sistema de reconhecimento baseado na abordagem sintática.

\subsection{3 - Abordagem Estrutural}

A idéia chave do reconhecimento de padrōes estrutural é a representação dos padrões por meio de dados simbólicos. Um exemplo de dados simbólicos é a descrição de animais armazenada em uma árvore, onde as folhas armazenam características como: tem quantas pernas, fala, vive no fundo do mar, etc. $O$ reconhecimento é realizado através da comparação da representação simbólica do novo padrão com as representações simbólicas dos padrões previamente 
armazenados. $\mathrm{Na}$ abordagem estrutural, a qualidade da informação sobre a classe é usada para estruturar o problema [Ripley, 96].

Dentre as técnicas mais conhecidas, esta o "structural matching", que pode comparar estruturas tais como: string, árvores $\Theta$ grafos. Nesta técnica 0 reconhecimento de padrōes estrutural é realizado por meio de comparações, seguindo o princípio da abordagem estrutural.

\subsection{4 - Abordagem Conexionista}

As conexões entre os neurônios em uma Rede Neural determinam fundamentalmente o comportamento da rede e como esse comportamento pode mudar com relação ao tempo. Por esta razão, o campo conhecido hoje como Redes Neurais foi originalmente chamado de Conexionista [Smith, 96]. Esta abordagem é muito importante para esta dissertação, por isso, foi dedicado o capítulo de Redes Neurais a ela.

\section{4 - Estrutura típica de um sistema de reconhecimento de padrões}

O primeiro passo para o desenvolvimento de um sistema de reconhecimento de padrões baseado em Redes Neurais é a obtenção de um conjunto representativo de padrões. Para isto, o sistema de reconhecimento de padrões normalmente tem um dispositivo (por exemplo, sensores) que captura os dados ou padrões a serem utilizados pelo sistema.

Após a obtenção dos dados, uma fase praticamente obrigatória se refere ao tratamento da informação bruta captada pelos sensores. Esta etapa tem o objetivo de filtrar ou minimizar ruídos e distorções que possam resultar do processo de aquisição dos dados, transformando os dados originais em informaçōes de melhor qualidade.

Também fazem parte desta etapa, em muitas aplicações, as operações de segmentação e normalização do sinal de entrada. Na segmentação o objetivo é a separação de padrões que possam ter sido apresentados interligados. $\mathrm{Na}$ normalização, a idéia é a modificação do sinal original de forma a reduzi-lo à escala mais adequada e a atender as restriçōes de limite do espaço de entrada. A 
normalização é feita para que os dados capturados pelo sistema em diferentes situaçōes tenham o mesmo peso no treinamento da rede.

Depois do processo de tratamento da informação bruta, existe o processo de extração de características. Este processo consiste na obtenção de medidas relevantes que possam ser usadas na caracterização dos padrōes. Essas características podem ser numéricas (como por exemplo a área ou volume ocupado por um objeto), simbólicas (como por exemplo a cor de um objeto), booleanas (possuem ou não uma característica), ou uma combinação dessas.

Uma outra fase é a seleção de características, que tem o objetivo de tomar 0 sistema computacionalmente viável, eficiente e reduzir a quantidade de informação a ser manipulada. A seleção deve ser eficiente a fim de manter as características relevantes dos padrões e minimizar a quantidade de informações desnecessárias. Um dos benefícios da seleção é a redução da dimensão do espaço do problema. Esta fase é importante, pois características irrelevantes ao problema não deveriam passar para a fase de aprendizado da rede.

Depois dos dados serem processados, uma última fase antes do treinamento do sistema é a divisão em conjuntos de treinamento e teste. Um problema desta fase é dividir o conjunto de padrões obtidos a fim de minimizar o erro de reconhecimento do sistema. Uma boa divisão dos conjuntos de treinamento e teste deve conter elementos representativos de todas as classes dos padrões captados pelo sistema. Desta forma, o sistema aprende de forma mais abrangente, analisando todas as classes possíveis.

A fase de treinamento consiste na utilização de exemplos representativos das classes de padrões que se quer reconhecer para a definição de representações desses padrões no sistema. Nesta fase, o sistema analisa os padrões de entrada e gera uma representação interna para estes padrões. Esta representação deve ser boa o suficiente para que possa ser empregada na fase de classificação, generalizando o desempenho da rede para padrões não vistos anteriormente.

$\mathrm{Na}$ fase de classificação um padrão é apresentado ao sistema, que deve decidir a que classe ele pertence. Nesta fase o sistema de reconhecimento de padrões está pronto para ser utilizado. 


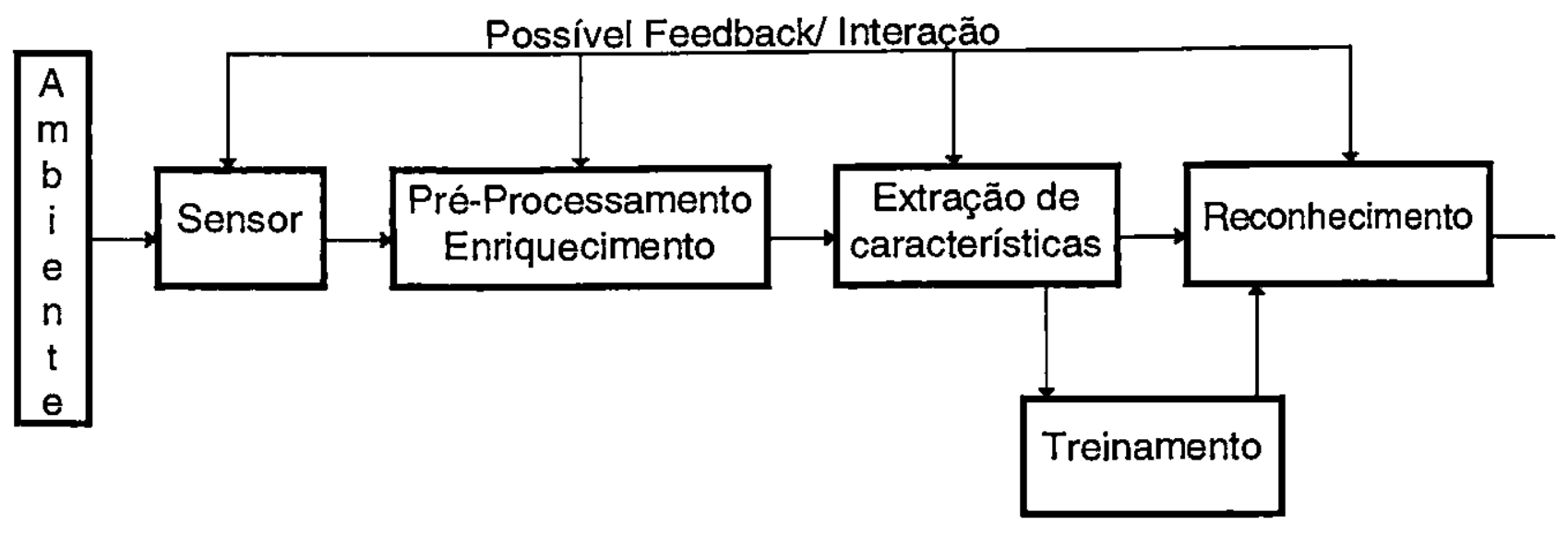

Figura 2.2 - Exemplo de um sistema Neural de Reconhecimento de Padrões.

A Figura 2.2 apresenta um esquema de um sistema de reconhecimento de padrões baseado em Redes Neurais. Note que existe a possibilidade de interação na fase de treinamento, mas isto depende do paradigma de aprendizado utilizado. O sensor descrito nesta figura pode ser um radar que captura imagens, ou um outro sistema de captação de dados. A finalidade deste sistema é classificar adequadamente os dados capturados pelo sensor.

\section{5 - Conclusão}

Este capitulo refere-se às técnicas para o Reconhecimento de Padrões. Existem várias abordagens para o Reconhecimento de Padrões. A primeira abordagem apresentada é a estatística, possuindo vários métodos baseados em probabilidade. A segunda, a sintática, é baseada em linguagem formais, trata o problema de reconhecimento em termos sintáticos. A terceira, a abordagem estrutural, realiza uma comparação entre a representação dos padrões e as representações das classes. $E$ por fim, a abordagem conexionista baseada na estrutura do cérebro humano. Nesta abordagem, o sistema aprende sobre os padrões de entrada alterando os pesos das conexões da rede. As Redes Neurais tem uma estrutura paralela e fornecem soluções eficientes para diversos problemas do mundo real.

Independe da abordagem empregada, um sistema de reconhecimento de padrōes tem uma estrutura típica. Iniciando com os sensores que são responsáveis pela 
captura dos dados, seguido pela fase de pré-processamento responsável pelo refinamento dos dados capturados. Logo após está a fase de extração de características que tem o objetivo de analisar as características representativas dos padrões. Em seguida existe a fase de treinamento que é responsável pela definição de representaçōes a partir dos padrōes representativos fornecidos pela fase de extração de características. E, por fim, vem a classificação que decide a classe a qual pertence um novo padrão apresentado ao sistema.

Dentre as principais abordagens de Reconhecimento de Padrões está a abordagem conexionista. Esta abordagem será vista em maiores detalhes no capítulo seguinte. 


\section{REDES NEURAIS ARTIFICIAIS}

\section{1 - Introdução}

As principais atividades do corpo humano são controladas pelo sistema nervoso. $O$ sistema nervoso é formado por um conjunto extremamente complexo de células, os neurônios. Eles têm um papel essencial na determinação do funcionamento e comportamento do corpo humano e do raciocínio [Llinás, 89].

Um neurônio típico é formado por dendritos, corpo central e axônio, vide Figura 3.1. Os dendritos são um conjunto de terminais de entrada e têm uma superfície irregular e muitos ramos. O axônio é um longo terminal de saída e apresenta uma superfície lisa com poucos ramos e de grande comprimento. O corpo central de uma célula nervosa é a região onde se encontra o seu núcleo. As forma e o tamanho dos neurônios podem variar em diferentes partes do sistema nervoso de acordo com sua função e desempenho.

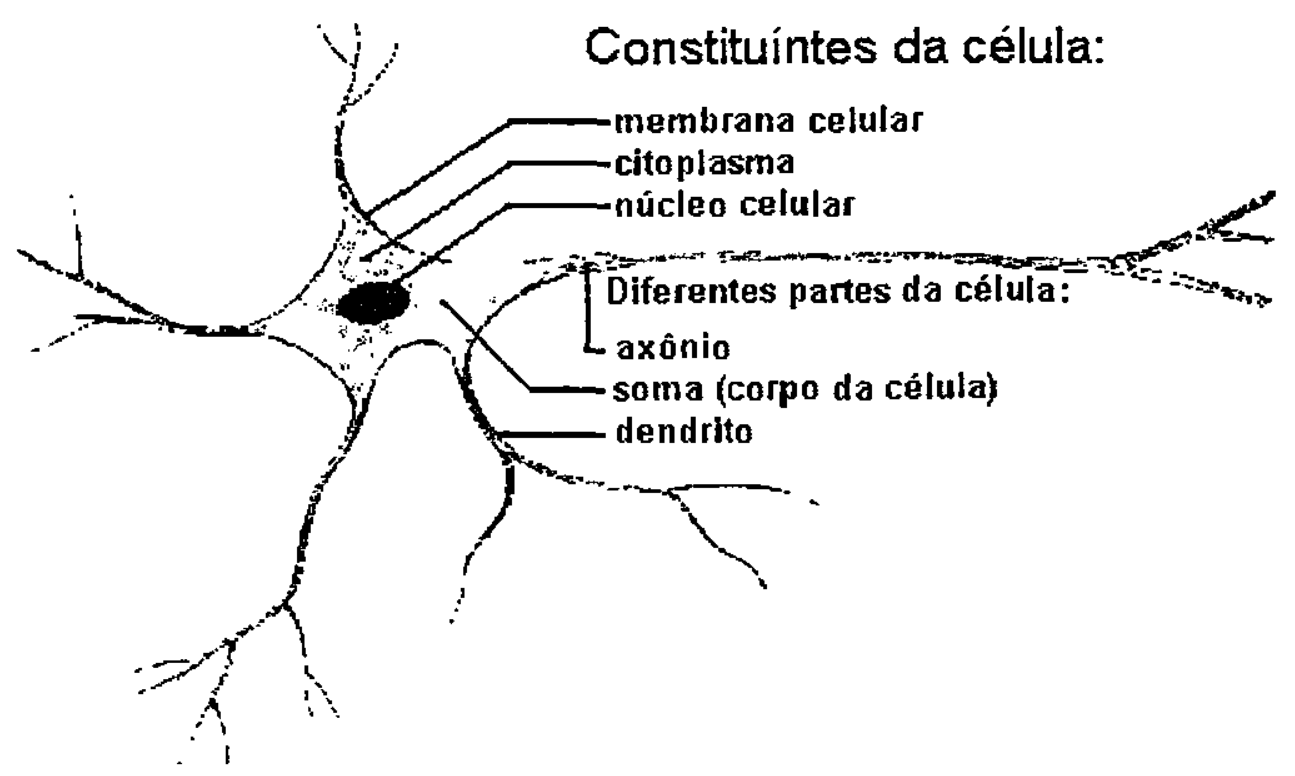

Figura 3.1 - Exemplo de célula nervosa. 
Os neurônios se comunicam através de sinapses. Sinapse é a região onde dois neurônios entram em contato e através da qual os impulsos nervosos são transmitidos entre eles. Os impulsos recebidos por um neurônio $A$, em um determinado momento, são processados. Atingido um dado limiar de ação, o neurônio $A$ dispara gerando um pulso. O pulso produz uma substância neurotransmissora que flui do corpo celular para o axônio, o qual pode estar conectado a um dendrito de um outro neurônio $B$. $O$ neurotransmissor pode diminuir ou aumentar a polaridade da membrana pós-sináptica, inibindo ou excitando a geração dos pulsos no neurônio $B$. Este processo depende de vários fatores, como a geometria da sinapse e o tipo de neurotransmissor.

Em média, cada neurônio forma entre mil è dez mil sinapses. O cérebro humano possui cerca de $10^{11}$ neurônios, e o número de sinapses é de mais de $10^{14}$, possibilitando a formação de redes muito complexas.

O cérebro é um sistema de processamento de informação altamente complexo, nãolinear e paralelo. A estrutura do cérebro e a sua capacidade de organizar seus neurônios torna possível o ser humano realizar certas tarefas, como por exemplo, reconhecimento de padrões, percepção e controle motor, muito mais rapidamente do que o mais rápido computador digital hoje existente.

Trabalhos em Redes Neurais Artificiais têm se inspirado na maneira como o cérebro processa suas tarefas, pela abordagem usada, que segue um caminho totalmente diferente do computador digital convencional.

As Redes Neurais Artificiais são técnicas computacionais que apresentam um modelo matemático inspirado na estrutura neural dos seres vivos $\theta$ que adquirem conhecimento através da experiência. Uma grande Rede Neural Artificial pode ter centenas ou milhares de unidades de processamento; já o cérebro de um mamífero pode ter muitos bilhões de neurônios [Llinás, 89].

Uma Rede Neural Artificial é uma arquitetura distribuída e massivamente paralela que tem a propensāo natural para armazenar conhecimentos e torná-los disponiveis para uso futuro. Parece-se com o cérebro em dois aspectos:

1. Conhecimento é adquirido através de um processo de aprendizagem.

2. Os pesos das conexões éntre neurônios, conhecidos como sinapses, são usados para armazenar o conhecimento. 
O procedimento utilizados para representar o processo de aprendizagem, comumente chamado algoritmo de aprendizagem, tem a função de modificar os pesos das conexões da rede buscando alcançar um objetivo. Redes Neurais são também referenciadas na literatura como neurocomputadores ou modelos conexionistas. A seguir será apresentado um histórico das pesquisas em Redes Neurais Artificiais.

\section{2 - Histórico de Redes Neurais Artificiais}

O interesse em Redes Neurais data do início da década de 1940, com o trabalho pioneiro de McCulloch e Pitts [Haykin, 94]. Warren McCulloch foi um psiquiatra e neuroanatomista que estudou por 20 anos a representação de eventos no sistema nervoso. Walter Pitts foi um matemático que se juntou a McCulloch em 1942. Em 1943 eles publicaram no Bulletin of Mathematical Biophysics um artigo com o título: "A Logical Calculus of the Ideas Immanent in Nervous Activity", que se tornou clássico, e recebeu muita atenção da comunidade que estudava o modelo do neurônio [McCullock, 43]. Um grupo da Universidade de Chicago, sob a liderança de Rashevsky, vinha estudando o neurônio pelo menos 5 anos antes da publicação do artigo [Haykin, 94].

Além de publicarem o artigo, McCulloch e Pitts provaram teoricamente que qualquer função matemática ou lógica pode ser implementada utilizando unidades soma de produtos [Haykin, 94]. Depois de McCulloch e Pitts, alguns pesquisadores se dedicaram à investigação de Redes Neurais.

Mais adiante, em 1949, Hebb sugeriu um método para que os parâmetros do modelo do neurônio de McCulloch-Pitts pudessem ser ajustados, mostrando assim como as redes neurais poderiam ser treinadas. Estes primeiros estudos das redes neurais biológicas formaram os fundamentos do que se tornou conhecido como Redes Neurais Artificiais (RNAs).

Rosemblatt em 1959 implementa a primeira rede neural, o perceptron e prova o teorema da convergência (se é possível classificar um conjunto de entradas, uma rede perceptron fará a classificação) [Haykin, 94].

Em 1960, Widrow e Hoff introduziram o algoritmo "Least Mean Square" (LMS), conhecido como mínimos quadrados, que usaram para treinar a rede o Adaline 
(elemento linear adaptativo) [Haykin, 94]. A principal diferença entre o "perceptron", apresentado por Rosemblatt, e o Adaline de Widrow, situa-se no procedimento de treinamento. Widrow e seus estudantes propuseram uma das primeiras redes neurais com múltiplos elementos adaptativos, que foi chamada de Madaline (múltiplo Adaline) [Haykin, 94].

Após a apresentação do perceptron em 1960, acreditava-se que redes neurais (perceptron) poderiam fazer qualquer coisa, ou seja, resolver qualquer problema. Em 1969, Minsky e Papert publicaram um livro, Perceptrons [Minsky, 69], onde os autores usaram uma elegante matemática para demonstrar que existiam limites para 0 perceptron com apenas uma camada intermediária. Mostraram que o mesmo não poderia lidar com problemas não linearmente separáveis, como, por exemplo, resolver o problema do "ou exclusivo" (XOR).

A publicação deste livro aliada, às limitaçōes dos computadores desta época, reduziu o suporte financeiro para conduzir projetos nesta área. Como resultado, as pesquisas com Redes Neurais foram substancialmente reduzidas pelo menos até o início dos anos 80 . Em meados dos anos 80 surgiram novos modelos que reacenderam o interesse pela área.

Grossberg apresentou, em 1980, uma nova rede que utilizava aprendizado competitivo, estabelecendo um novo princípio de auto organizaçāo. Grossberg apresentou uma nova classe de Redes Neurais baseada na teoria da ressonância adaptativa (a família das redes ART) [Grossberg, 82].

Em 1982, Hopfield usou uma função de energia para formular uma nova maneira de entender os cálculos feitos pelas redes recorrentes com conexões de sinapse simétricas, mostrando que as Redes Neurais podem ser tratadas como sistemas dinâmicos [Hopfield, 82]. Esta particular classe de Redes Neurais com feedback atraiu grande atenção nos anos 80 , e com o tempo estas redes tornaram-se conhecidas como redes de Hopfield.

No mesmo ano, Kohonen publicou um artigo no qual utilizava mapas auto organizáveis como uma estrutura uni ou bi dimensional que também empregavam aprendizado competitivo [Kohonen, 82].

Certamente o algoritmo de aprendizagem que causou maior impacto foi 0 "backpropagation", desenvolvido por Rumelhart, Hinton e Willian em 1986 [Rumelhart, 
86]. Este impacto se deu, principalmente, após a publicaçāo do livro, "Parallel Distribuited Processing" (Processamento Paralelo Distribuído): Explorações na Microestrutura do Conhecimento, escrito por Rumelhart e McClelland. 0 "backpropagation" é utilizado para treinar redes perceptron multicamadas.

O algoritmo "backpropagation" foi desenvolvido independentemente por outros pesquisadores: Werbos em 1974, Parker em 1985 e Le Cun em 1985 [Haykin, 94]. Somente após uma década, a comunidade científica tomou conhecimento da Tese de doutorado de Werbos, defendida em Harvard em agosto de 1974, que propôs um algoritmo para o cálculo do gradiente de modo reverso. Este algoritmo foi aplicado para modelos de redes gerais, podendo ser aplicado em Redes Neurais como um caso especial.

Em 1988, Broomhead e Lowe descreveram um modelo de Redes Neurais que utiliza funçōes base radial, conhecida na literatura como "radial basis function" (RBF). A idéia básica da RBF lembra bastante o método de funçōes potenciais desenvolvido por Bashkirov, Braverman e Muchnick em 1964 [Haykin, 94]. O livro clássico "Pattern Classification and Analysis of Scenes" (Classificação de Padrōes e Análise de Cenas), escrito por Duda e Hart em 1973, apresenta uma descrição do método de funções potenciais .

Broomhead e Lowe deram sua contribuição ligando o projeto de redes neurais com uma importante área da análise numérica e também com filtros adaptativos lineares. Um trabalho suplementar apareceu em 1990 com Poggio e Girosi, que enriqueceram a teoria de redes RBF aplicando a teoria da regularização de Tikhonov [Poggio, 90]. Na próxima seçāo serāo apresentadas as principais Redes Neurais Artificiais para esta dissertação.

\section{3 - Principais Redes Neurais Artificiais}

Existem variados tipos de Redes Neurais, cada um com sua própria estrutura e método de aprendizado. Assim as redes possuem características diferentes, que podem facilitar a resolução de um problema, caso a rede mais apropriada seja escolhida.

As redes escolhida para este trabalho foram: Multi-Layer Perceptron (MLP), Radial Basis Function (RBF) e Cascade Correlation. A rede MLP foi escolhida para participar 
do sistema de combinação, por dividir classes (regiōes) de padrões com hiperplanos. Além disso é a rede mais utilizada para Reconhecimento de Padrões. A rede RBF foi escolhida por dividir classes (regiōes) de padrões com hiper-elipsóides. A rede Cascade Correlation foi escolhida por possuir uma nova técnica de aprendizado, 0 aprendizado construtivo. As subseções seguintes descrevem, de forma sucinta, as redes utilizadas nesta dissertação.

\subsection{1 - Perceptron Multicamadas}

Minsky e Papert demonstraram que redes de uma única camada não são capazes de solucionar problemas que não sejam linearmente separáveis, desestimulando as pesquisas em Redes Neurais. Eles argumentaram que enquanto não fosse desenvolvido um método de treinamento para redes com mais de uma camada, as Redes Neurais seriam suscetíveis a esta limitação [Minsky, 69]. Este problema foi resolvido com o surgimento do algoritmo backpropagation.

Nas redes com mais de uma camada, cada camada tem uma função especifica. A camada de saída recebe os estímulos da última camada intermediária e constrói o padrão que será a resposta da rede. As camadas intermediárias funcionam como extratores de características, seus pesos são uma codificação de características apresentadas nos padrōes de entrada e permitem que a rede crie sua própria representação, mais rica e complexa, do problema.

O desenvolvimento do algoritmo de treinamento backpropagation, por Rumelhart, Hinton e Williams em 1986 [Rumelhart, 86], precedido por propostas semelhantes ocorridas nos anos 70 e 80 [Werbos, 74; Parker, 85], mostrou ser possível um procedimento de treinamento para redes com mais de uma camada (vide Figura 3.2). O algoritmo backpropagation popularizou a utilização de redes com mais de uma camada, as redes do tipo MLP, do inglês Multi-Layer Perceptron.

Durante o treinamento com o algoritmo backpropagation, a rede opera em uma seqüência de dois passos. Primeiro, um padrão é apresentado à camada de entrada da rede. A atividade resultante flui através da rede, camada por camada, até que a resposta seja produzida pela camada de saída. No segundo passo, a saída obtida é comparada à saída desejada para esse padrāo particular. Se esta não estiver correta, o erro é calculado. 


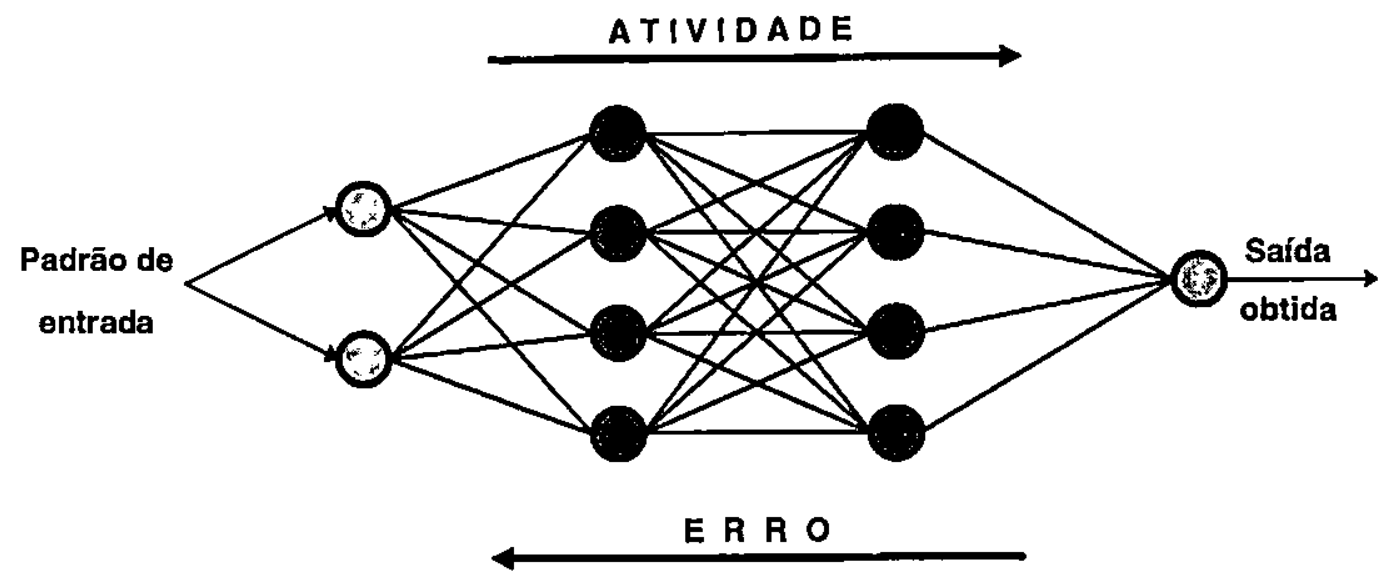

Figura 3.2 - Backpropagation.

O erro é propagado a partir da camada de saída até a camada de entrada, e os pesos das conexōes das unidades das camadas internas vão sendo modificados conforme o erro é retropropagado. A Figura 3.2 apresenta um esquema de treinamento da rede MLP com o algoritmo backpropagation.

\subsection{2 - Radial Basis Function (RBF)}

Funções base radiais são uma classe especial de funçōes cujo valor diminui ou aumenta em relação à distância de um ponto central. Estas funçōes podem ser empregadas em qualquer tipo de rede (com uma ou mais camadas). Contudo, depois do artigo de Broomhead e Lowe em 1988, é comum associar a rede de Funções de Base Radial ou rede RBF a uma rede neural com apenas uma camada interna.

Na rede RBF, o valor de ativação de cada neurônio da camada intermediária é dado em função da distância Euclidiana entre o vetor de entrada e o vetor centro da unidade. Os valores de ativação das unidades internas são combinados linearmente com os pesos das conexões entre a camada interna e a camada de saída para formar a saída da rede.

Quando o número de funções base radiais é igual ao número total de padrões de treinamento, com centros situados sobre cada vetor de entrada, a rede RBF mapeia exatamente o vetor de entrada para o vetor de saída. Porém esta interpolação exata é indesejável, principalmente no caso de exemplos com ruído, pois gera o problema de overfitting. 
Uma das maneiras de tratar o problema é considerar o número $m$ de funções radiais menor que o número total de padrões de treinamento $\mathbf{N}$. Além disso, as posições dos centros não devem ser restritas apenas aos vetores de entrada. $A$ escolha das novas posições é feita durante treinamento da rede.

O aspecto chave da rede RBF é a distinção entre o papel dos pesos da primeira e da segunda camada. Seguindo esta divisão, o procedimento de treinamento da rede RBF é dividido em dois estágios: No primeiro, os parâmetros das funçōes base radiais (os centros) são determinados por métodos não supervisionados. Neste estágio, somente o conjunto dos dados de entrada é usado para determinar os parâmetros (os centros) das funções base (funções de ativação). No segundo estágio, as funções base são mantidas fixas, enquanto os pesos da segunda camada são ajustados. Neste estágio, os pesos da rede são determinados através da solução de um problema linear [Bishop, 96].

A função da camada interna da rede RBF é transformar um conjunto de exemplos não separável linearmente em um conjunto separável linearmente. Com isso, a camada de saída receberá valores que são linearmente separáveis. O problema de ajuste de pesos, portanto, reduz-se, a um problema linear semelhante ao ajuste de pesos da rede Adaline [Haykin, 94].

A rede RBF pode ser considerada como uma evolução das redes MLP. A forma da rede $\mathrm{RBF}$ é muito semelhante à da rede MLP com apenas uma camada escondida. $A$ grande diferença entre estas redes está nas suas funções de ativação e nos seus algoritmos de treinamento.

Cada função de ativação da camada intermediária da rede RBF requer um "centro" e um parâmetro escalar. Uma função que pode ser utilizada como ativação é a função Gaussiana. O aprendizado na camada intermediária é executado usando um método não supervisionado, tipicamente um algoritmo de "cluster", um algoritmo de "cluster" heurístico, ou um algoritmo supervisionado para achar os centros (nós na camada escondida). $O$ algoritmo mais utilizado para determinar os centros é o algoritmo de Lloyd ou K-means [Hush, 93].

$A$ rede RBF define um conjunto de funções geralmente não lineares que particionam o espaço de padrões de uma forma diferente da MLP. Na Figura 3.3 está um exemplo da estrutura de uma rede RBF. 


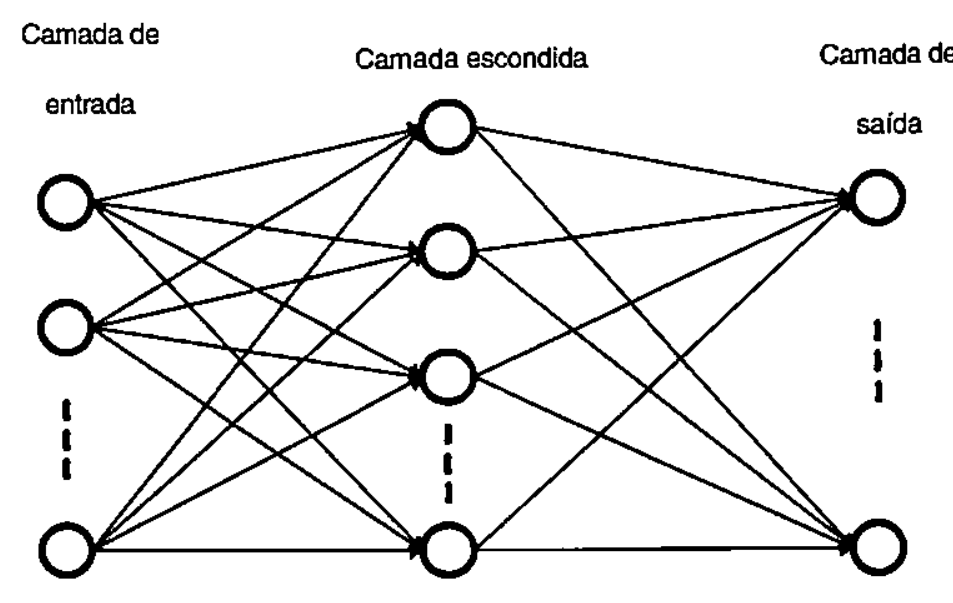

Figura 3.3 - RBF [Beale, 94].

Uma importante característica natural da rede RBF é observada utilizando-a como classificador de padrōes. Suponha um conjunto de dados que está dividido em três classes. A rede MLP pode separá-lo gerando hiperplanos que dividem as classes. Já a rede RBF separa as classes em núcleos. A rede RBF separa as regiões utilizando funções de núcleos locais, hiper-elipsóides, para dividir seu espaço de padrōes. A divisão do espaço de padrões em hiper-elipsóides possibilita maior precisão na classificação dos padrões de entrada.

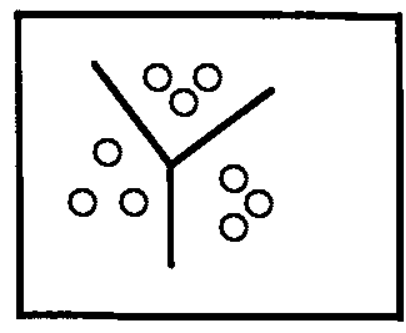

(a)

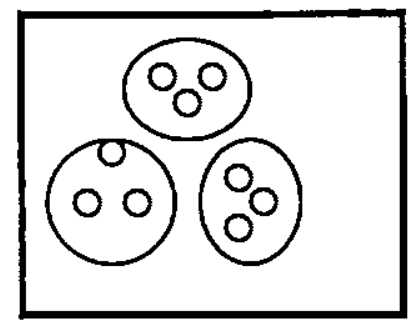

(b)

Figura 3.4 - Classificando padrões MLP e RBF. 
Na Figura 3.4 está um exemplo de como as redes MLP e RBF podem classificar os mesmo dados. Na parte (a) está a forma como a MLP classifica estes dados, na parte (b) está a forma como a RBF os classifica [Bishop, 96].

\subsection{3 - Cascade Correlation}

Umas das preocupaçōes durante a definição de uma rede é a sua arquitetura. Uma maneira de melhorar o desempenho de uma rede neural diz respeito à escolha de uma boa arquitetura. Uma das técnicas de otimização de arquitetura de redes neurais é a utilização de aprendizado construtivo.

No aprendizado construtivo é permitido, durante a fase de treinamento da rede neural, inserir novos nós intermediários. Assim, enquanto a rede é treinada, sua arquitetura está em construção (ou crescimento). Neste tipo de aprendizado a rede começa com um número mínimo de nós, ou seja, os nós de entrada e os nós de saída. $O$ treinamento se incumbe de inserir nós intermediários à rede. Um das redes construtivas mais utilizadas é a rede cascade correlation [Fahlman, 90].

O rede Cascade Correlation emprega uma nova metodologia de aprendizado supervisionado para RNAs. Ao invés de apenas ajustar os pesos em uma rede de topologia fixa; a arquitetura Cascade Correlation começa com uma rede mínima, ilustrada na Figura 3.5. Durante o treinamento, ela modifica pesos e adiciona unidades escondidas.

A arquitetura Cascade Correlation tem algumas vantagens sobre os demais modelos: aprende muito rápido; determina o tamanho e topologia da rede; e não perde o conhecimento já obtido quando novos padrōes forem apresentados para o treinamento da rede.

A rede Cascade Correlation combina duas idéias chaves. A primeira é a arquitetura em cascata, na qual unidades escondidas são adicionadas à rede uma de cada vez e não mudam depois de adicionadas. Essas unidades escondidas adicionadas à rede são conectadas às unidades de entrada, de saídas e às unidades intermediárias existentes, se houver; formando uma cascata de unidades. A segunda idéia é o algoritmo de aprendizado construtivo, o qual cria e instala novas unidades escondidas. 


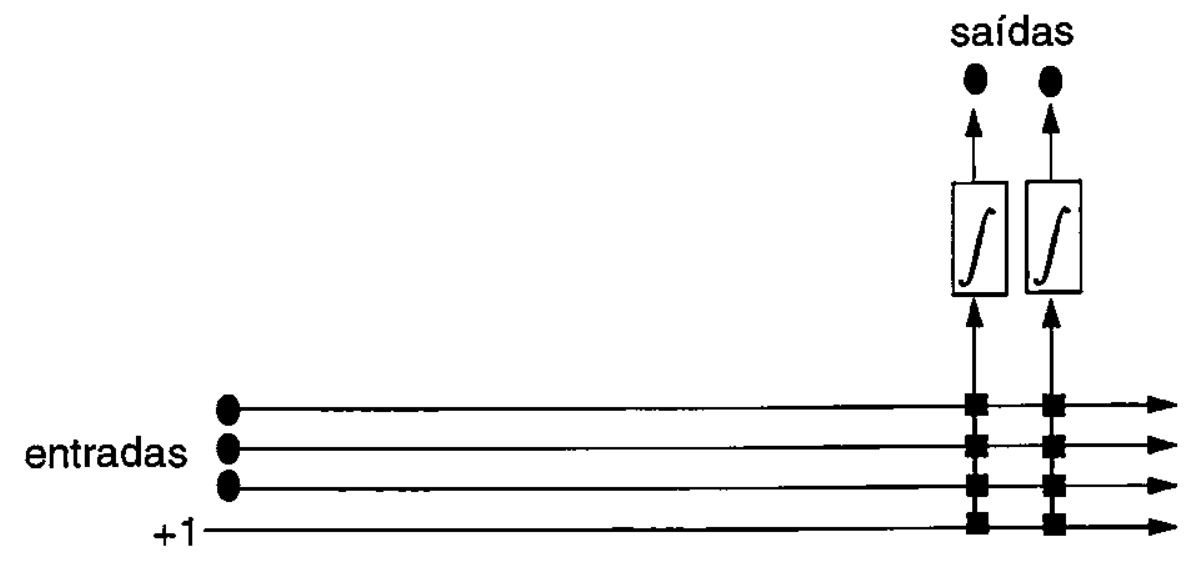

Figura 3.5 - Cascade Correlation no formato inicial.

A arquitetura cascade começa com as entradas e as unidades de saída necessárias ao problema em questão, mas com nenhuma unidade escondida, vide Figura 3.5. Todas as unidades de entrada são conectadas a todas as unidades de saída.

As unidades escondidas são adicionadas uma a uma. Cada unidade escondida recebe uma conexão de cada unidade de entrada original da rede e também de todas unidades escondidas pré-existentes, vide Figura 3.6. Os pesos das unidades escondidas são congelados no instante em que um novo nó é adicionado à rede. Somente as conexões de saída são treinadas repetidamente.

As conexōes diretas da entrada/saída são treinadas utilizando o conjunto de dados de treinamento. $O$ algoritmo de treinamento destas unidades pode ser 0 algoritmo de aprendizado perceptron ou qualquer outro algoritmo conhecido para redes de uma única camada.

$\mathrm{Na}$ fase de treinamento, quando um novo neurônio for adicionado à rede, é calculado o erro cometido pela rede e realizado o ajuste dos seus pesos da rede. Este ciclo (cálculo do erro e ajuste dos pesos) pára quando uma redução não significativa do erro ocorreu depois de $\mathbf{N}$ de ciclos de treinamento.

Se o erro está aceitável o treinamento é interrompido, caso contrário deve haver algum erro adicional na rede, que pode ser reduzido. Para isto é adicionado uma nova unidade escondida na rede, usando o algoritmo de criação, e recomeçam os $\mathbf{N}$ ciclos de treinamento da rede. Rede que possui agora um novo neurônio na camada intermediária. 


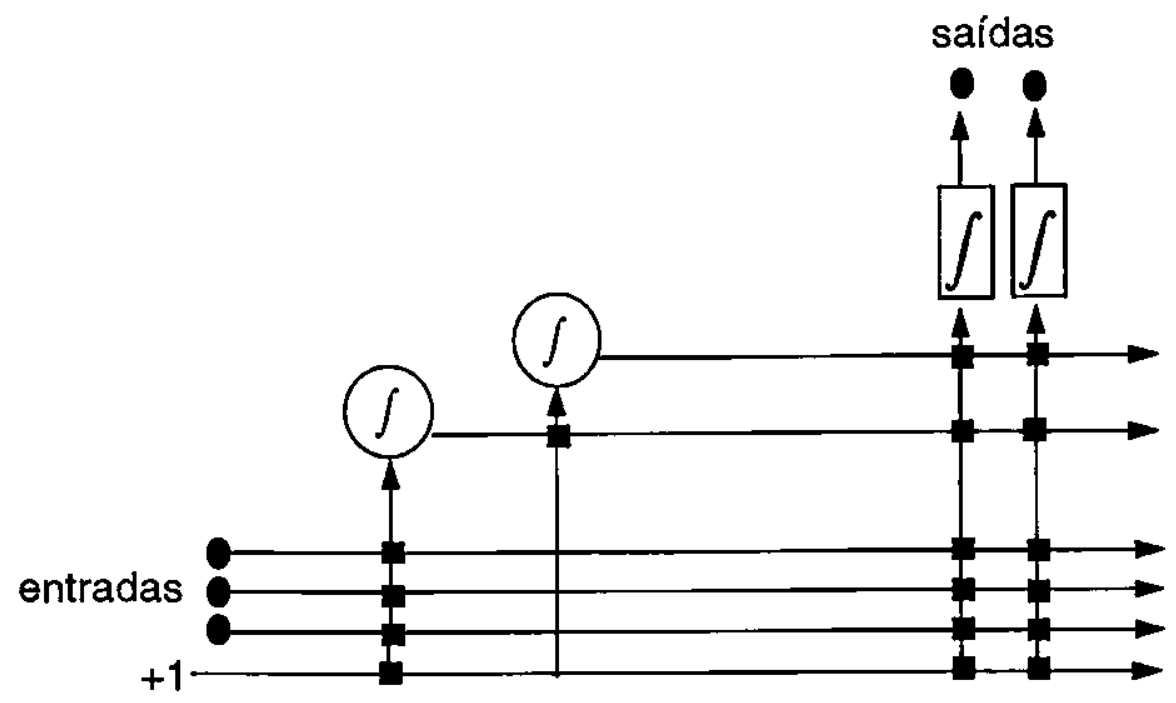

Figura 3.6 - Cascade Correlation depois da segunda unidade escondida adicionada.

A fase de treinamento pára quando, mesmo depois da inserção de um novo neurônio na camada intermediária, o erro não reduziu significativamente [Fahlman, 90].

\section{4 - Conclusão}

Neste capítulo são apresentados conceitos básicos de Redes Neurais Artificiais, um histórico das principais pesquisas na área e os modelos de Redes Neurais utilizados neste trabalho.

As Redes Neurais utilizadas neste projeto são as redes: Multi-Layer Perceptron, Radial Basis Function e Cascade Correlation. A rede Multi-Layer Perceptron foi escolhida para participar do sistema de combinação, por dividir classes (regiōes) de padrões com hiperplanos. Além disso, esta é a rede mais utilizada para Reconhecimento de Padrões, pois já apresentou bons resultados para este tipo de aplicações.

A rede Radial Basis Function foi escolhida por dividir classes (regiōes) de padrões com hiper-elipsóides. Uma outra característica desta rede é a rapidez na fase de treinamento. 
A rede Cascade Correlation foi escolhida por possuir uma nova técnica de aprendizado, o aprendizado construtivo. Uma das vantagens da rede cascade correlation é que a própria rede determina sua topologia.

Existem várias aplicaçōes para as Redes Neurais, uma dela é o reconhecimento de alvos. Este tópico será tratado no próximo capítulo. 


\section{1 - Introdução}

Reconhecimento automático de alvos (Automatic Target Recognition, ATR) é um problema muito abrangente e de grande importância para as aplicações industriais $\theta$ militares. Um problema típico de ATR é o reconhecimento de tanques de guerra. Normalmente as imagens desses tanques são imagens provenientes de radar, semelhante à imagem da Figura 4.1 .

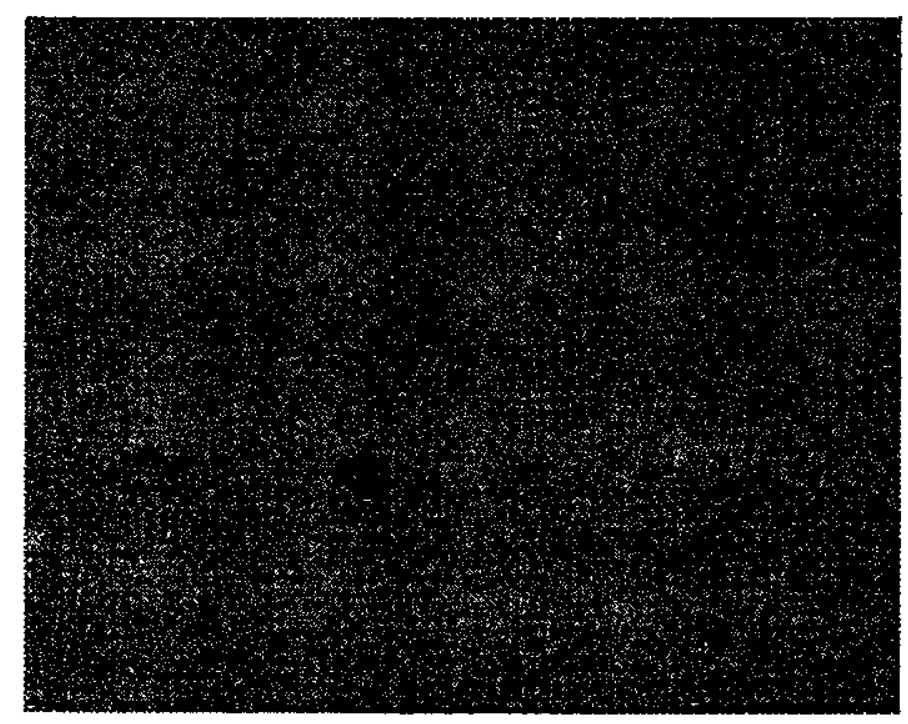

Figura 4.1 - Imagem de um alvo.

Várias abordagens recentes de ATR são baseadas na forma como os seres humanos e os animais utilizam suas capacidades de percepção e reconhecimento. Uma boa ferramenta para lidar com este problema são as Redes Neurais que, além de ser um bom método para solucionar os problemas de ATR, possuem respaldo biológico. 
Os Modelos de Redes Neurais Artificiais têm sido muito empregados no desenvolvimento de sistemas ATR. Os modelos mais usados nas aplicações de Redes Neurais, incluindo ATR, são baseadas no modelo Perceptron multicamadas [Rogers, 95].

Há diversas maneiras para agrupar os diferentes problemas de ATR. Uma dessas maneiras é a caracterização em termos dos sensores de dados que o sistema utiliza. Um sistema ATR pode utilizar uma variada gama de tipos de sensores para detectar um alvo em uma aglomeração de objetos. Na Figura 4.1 está um exemplo de uma imagem de radar. Note que existe uma dificuldade de reconhecer os objetos nesta imagem.

Dentro do projeto de um sistema ATR, existe um amplo conjunto de operações necessárias para o bom funcionamento do sistema. O esboço de um sistema ATR está representado na Figura 4.2.

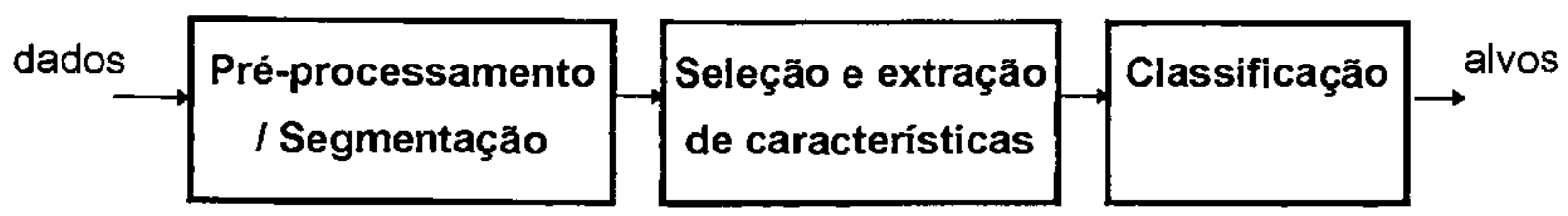

Figura 4.2 - Visão geral do reconhecimento automático de alvos.

A fase de pré-processamento e segmentação retira os ruídos das imagens e separa os objetos em imagens individuais. A fase de seleção e extração de característica retira da imagem características e seleciona as principais para serem utilizadas como entrada na fase de classificação. A fase de classificação classifica objetos em classes de acordo com suas características.

Nas seções seguintes serão discutidas, com mais detalhes, as fases de um sistema ATR, incluindo o conjunto de dados relevante à aplicação, pré-processamento e segmentação, seleção e extração de características e, por fim, a classificação.

\section{2 - O conjunto de dados ATR}

Provavelmente a primeira decisão tomada no projeto de um sistema ATR diz respeito ao tipo de sensor usado para capturar as medidas dos alvos que serão 
reconhecidos. Apesar de existirem muitos fatores que influenciam esta escolha, uma importante consideração é a habilidade de separar as classes no espaço de medidas. As fases de segmentação, extração de características e classificação podem ser extremamente simplificadas pelo uso do sistema sensorial apropriado.

Existe uma grande variedade de sensores no mercado. Alguns sensores mais conhecidos estão descritos abaixo [Nasrabadi, 97]:

- Forward-Looking InfraRed (FLIR): Esse sensor capta características térmicas dos alvos para construir sua imagem. Pelo uso da termodinâmica, o sensor possui uma alta resolução angular $e$ alto contraste entre $\circ$ alvo e $\circ$ fundo da imagem. Sua operabilidade é diurna e noturna. O FLIR é afetado pela chuva, neblina e névoa. $O$ sensor FLIR tem uma pobre penetração em nuvens e folhagens. $O$ seu alcance na faixa atmosférica é de 10 a $15 \mathrm{Km}$.

- Visible: Esse sensor captura a imagem do alvo através da projeção de luz. 0 sensor Visible possui uma alta resolução de imagem. Sua operabilidade é somente diurna. Ele é afetado pelas condições do ambiente e não tem penetração nas folhagens. O seu alcance na faixa atmosférica é limitado pelas condições de visibilidade. Ele possui um baixo contraste entre o alvo e o fundo da imagem.

- Laser Radar: Esse sensor também utiliza luz para produzir as imagens do alvo. Possui uma resolução alta. Sua operabilidade é diurna e noturna. Ele é ligeiramente afetado pela chuva, neblina e névoa. Apresenta uma pobre penetração em folhagem. O Laser Radar tem uma tecnologia complexa. Esse sensor exige um longo tempo sobre o alvo para poder construir a imagem. Seu alcance na faixa atmosférica é de aproximadamente $5 \mathrm{Km}$.

- Microwave Millimeter Wave (MMW): Esse sensor utiliza microondas para gerar as imagens do alvo desejado. Sua resolução é moderada. Ele é menos sensível aos efeitos do tempo que o sensor Laser Radar. Sua operabilidade é diurna e noturna. $O$ seu alcance atmosférico pode ser muito grande. A penetração nas folhagens é mais eficiente com o uso de baixa freqüência de transmissão das microondas.

- Synthetic Aperture Radar (SAR): Esse sensor utiliza a emissão/recepção de pulsos eletromagnéticos para produção da imagem do alvo. Sua operabilidade é diurna e noturna. Ele tem um alto grau de contraste entre o alvo e o fundo da imagem. 
Existem algoritmos desenvolvidos para vários sensores diferentes. Isso acontece, porque cada sensor gera um tipo de imagem que facilita o reconhecimento do alvo em alguns aspectos e dificulta em outros.

Um dos sensores mais utilizados é o sensor SAR. Este tipo de sensor teve origem em 1940, quando a Marinha dos Estados Unidos adotou um código chamado radar. Este código era usado para detecção de objetos [Koch, 95]. Com o passar do tempo, algumas inovações foram propostas para este sinal, que levaram ao desenvolvimento de um sistema capaz de detectar sinais geradores de imagens de radar de alta resolução chamada SAR. O desenvolvimento desta técnica de capturação permitiu aos radares analisar alvos em locais com pouca luminosidade, tais como cavernas, grutas e etc.

Imagens geradas por radares de microondas apresentam muitas diferenças em relação às imagens ópticas (um exemplo de imagens ópticas são as fotografias). Nas imagens SAR o tamanho do objeto não varia com a distância do radar ao objeto. $O$ radar pode retornar importantes informações sobre as características do tamanho do alvo, enquanto as imagens ópticas possuem poucas informações sobre o tamanho do objeto, e estas informações dependem da distância do dispositivo que captura a imagem óptica do objeto. Um problema das imagens SAR é que é dificil, para olhos não treinados, interpretá-las.

Depois de capturados os dados e obtidas as imagens é necessário um refinamento desses dados, esta fase é conhecida como pré-processamento e segmentação.

\section{3 - Pré-processamento e Segmentação}

Pré-processamento e segmentação podem ser as tarefas mais dificeis em um sistema ATR. O pré-processamento é necessário quando os dados para o sistema ATR têm características de baixo contraste e embaralhamento dos alvos na imagem [Rogers, 95].

Um dos primeiros algoritmos executado no pré-processamento é um algoritmo de filtro. Este tipo de algoritmo tem por objetivo retirar ruido das imagens. O ruido pode ser muito prejudicial ao reconhecimento, pois pode levar um alvo pertencente a uma classe A ser considerado desconhecido pelo ruido ou pertencente a uma outra classe. 
O algoritmo seguinte é o de segmentação ou detecção de objetos na imagem. Este algoritmo isola o objeto de interesse na imagem. Por exemplo, se o objetivo é reconhecer automóveis, então as imagens devem ter apenas automóveis. Assim, o sistema não perde tempo com o fundo ou outros objetos presentes na imagem. $O$ grande problema de detecção acontece quando as imagens estão sobrepostas.

Existe uma estratégia que aplica um algoritmo de deteç̧ão sobre uma imagem para localizar regiöes que podem conter objetos de interesse, este processo é chamado de "cueing" [Koch, 95].

Seguem abaixo exemplos de alguns algoritmos usados na fase de préprocessamento e segmentação:

1. C-Far ( Cell averaging Constant False Alarm Rate algorithm), [Koch, 95];

2. Center Surround Retina, [Koch, 95];

3. Scanning Supervised Learning Segmentation, [Rogers, 95];

4. Scanning Windows Sar Segmentation using Wavelets [Rogers, 95];

5. Unsupervised Hyperspectral Segmentation, [Rogers, 95];

Os algoritmos nomeados acima săo desenvolvidos para dados diferentes. Por exemplo, seqüência de imagens, imagens provenientes de radar, imagens provenientes de fotografias.

Depois que a imagem não apresenta mais ruídos prejudiciais e que o objeto alvo do reconhecimento está isolado, vem à fase de extraçăo e seleção de características.

\section{4 - Extração e seleção de características}

O desafio da extração de características é retirar informações dos dados préprocessados capazes de caracterizar unicamente o alvo, fornecendo uma separação suficiente entre um alvo e um objeto năo alvo ou uma classificação correta dos alvos. A seleçăo tem por objetivo escolher o mínimo de características que mantenha a integridade do objeto, reduzindo desta forma a dimensão do espaço de características. 
Uma boa razão para reduzir o conjunto de características é o tempo de treinamento do modelo utilizado pelo sistema. O número de padrões de treinamento cresce exponencialmente tão rápido quanto o número de características [Rogers, 95].

A razão deste crescimento é que a complexidade da classificação depende do número de características. Quanto maior o número de características normalmente mais complexa será a classificação. A complexidade para classificar objetos que possuem apenas uma característica é decidir se o objeto em questão possui a característica ou não. Enquanto que a complexidade para classificar objetos com 1000 características é muito maior, requerendo um sistema mais avançado.

Um método muito utilizado para selecionar características é a transformação Karhunen-Loeve (Karhunen-Loeve Transformation, KLT) também chamada de análise dos componentes principais (Principal Component Analysis, PCA) [ABBA, 92]. Este método determina as características mais relevantes para a classificação do padrão. Para executar esta tarefa o método utiliza combinação linear.

Um outro método utilizado é a aplicação das Redes Neurais com aprendizado não supervisionado para seleção de características. Linsker em 1988 mostrou que redes adaptativas podem se auto-organizar para descobrir caracteristicas relevantes, isto é semelhante ao aprendizado presente no visual córtex dos mamiferos [Koch, 95].

Depois de aplicado um método de extração e seleção de características, pode-se então passar para a fase de classificação, que é o tema da próxima subseção.

\section{5 - Classificação}

Depois de recebidos os dados dos sensores e feito todos os procedimentos necessários, reconhecer os alvos é o último processo no sistema ATR. Para realizar esta tarefa, existem dois principais grupos de métodos, os conexionistas e os estatísticos.

Os métodos conexionistas podem ser associados a sistemas de aprendizado supervisionado ou não supervisionado. No caso do sistema ser supervisionado, o conjunto de dados para o treinamento da rede deve conter as características dos alvos e também a classe que os alvos pertencem. Neste tipo de sistema, o processamento é feito em duas fases. A primeira fase é a de treinamento, na qual o conjunto de dados é 
apresentado à rede, que irá representar este conjunto internamente através dos pesos de suas conexões. A segunda fase é a classificação propriamente dita, em que padrões desconhecidos são apresentados à rede e esta irá classificá-los em uma de suas classes do treinamento. A rede pode também classificar um ou mais padrões como desconhecido.

Quando o sistema conexionista é não supervisionado, os seus dados não possuem a determinação da classe que o padrão pertence. Neste caso, o próprio sistema divide os padrões em classes. Quando um padrão desconhecido é apresentado ao sistema ele decidirá se o classifica em uma classe já conhecida ou cria uma nova classe para classificá-lo.

Nos métodos estatísticos, a classificação de um padrão é feita através de uma comparação entre as suas características e as características correspondentes a cada uma das classes. O padrão é associado à classe que for mais semelhante.

Existem vários algoritmos para classificação de padrões estatísticos, como exemplo podem ser citados: inferência bayesiana, algoritmo Robbins-Monro, Estimação de densidade, $\mathrm{K}$ vizinhos mais próximos [Bishop, 95].

Na próxima subseção será apresentado um exemplo prático de um sistema de reconhecimento de alvo.

\section{6 - Um exemplo de reconhecimento e classificação de imagens}

No artigo [Bernardon, 95] é descrito um sistema de reconhecimento e aprendizado automático de alvos usando imagens SAR (Synthetic Aperture Radar). O objetivo do projeto do sistema de reconhecimento é o processamento e a classificação de imagens $2 \mathrm{D}$.

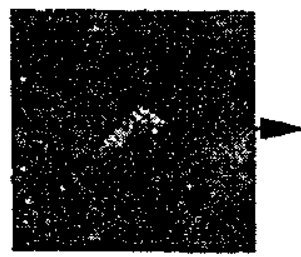

Original Image

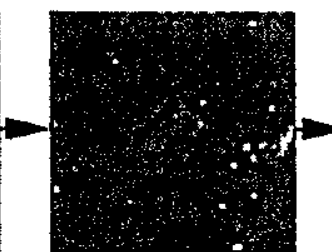

Center

Surround

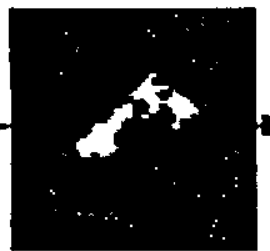

Binary

Features

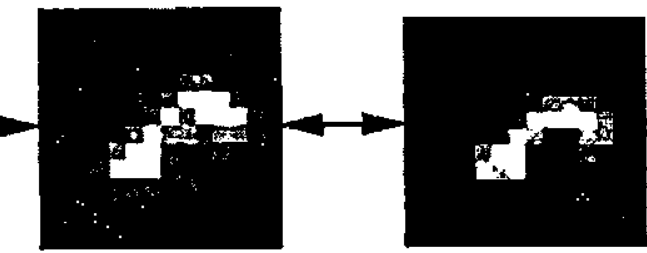

Receptive

Fields
Best Match

Exemplar (conf $=.938$ )

Figura 4.3 - Exemplo do processamento das imagens. 
Sua base de dados é composta por tanques e morteiros. Está apresentado na Figura 4.3 um exemplo de processamento realizadas nas imagens SAR. A imagem original é a fotografia de um tanque que esta em movimento. As imagens seguintes são os resultados do pré-processamento realizado na imagem anterior da seqüência, o nome do pré-processamento utilizado está embaixo de cada imagem. No final da seqüência está a imagem sendo comparada com uma imagem armazenada no sistema, esta comparação é feita pelo classificador usando as características de cada imagem.

Este sistema de reconhecimento apresenta vários componentes: (a) uma entrada que extrai características dos locais com alto contraste, (b) uma fase de detecção para localizar e mascarar pixels apagados, (c) uma fase de codificação de características (d) um estágio de aprendizado e reconhecimento, que aprende a reconhecer os alvos a partir de suas características, e realiza o reconhecimento. Um esquema do sistema é apresentado na Figura 4.4.

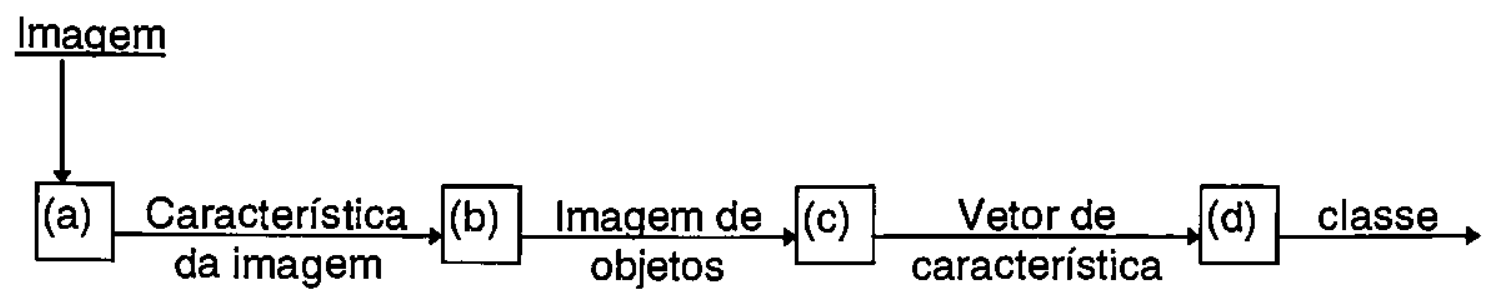

Figura 4.4 - Um exemplo de um sistema de reconhecimento de alvos.

Para a classificação foi usada uma rede ART-2A [Bernardon, 95], um método conexionista utilizado em diversas aplicaçōes. Os resultados obtidos com apenas duas classes, tanques e morteiros, foram muito bons.

O bom desempenho deste sistema foi favorecido pela pequena quantidade de classes. Esta aplicação foi escolhida por se tratar de uma aplicação simples que exemplifica o uso de imagens SAR e o processamento efetuado nestas imagens. Além disso, a aplicação concluiu com êxito seus objetivos. Na próxima subseção será apresentada a conclusão deste capítulo. 


\section{7 - Conclusão}

Este capítulo refere-se às etapas e recursos utilizados no desenvolvimento de um sistema de reconhecimento automático de alvos ATR. Os problemas a serem tratados neste tipo de sistema começam com a escolha de um sensor adequado ao problema em questão. A sensibilidade do sensor $\theta$ o tipo de informação que este transmite são fatores importantes para a sua escolha. Esta fase é de grande importância para o bom desempenho das fases seguintes, pois captura as informações pertencentes ao ambiente que serão utilizadas para a classificação. Esta captura deve ser criteriosa, afim de que nenhuma característica relevante ao problema passe desapercebida.

A segunda etapa é a fase de Pré-processamento e Segmentação da informação recebida. O pré-processamento é necessário quando os dados fomecidos pelo sensor apresenta baixo contraste $\theta$ embaralhamento dos alvos, neste caso o préprocessamento ameniza o ruído dos dados. A segmentação tem por objetivo a separação de alvos que possam ter sido interligados na captura dos mesmos.

A seguir vem a fase de extração e seleção de características. A extração de características tem o objetivo captar informações dos alvos. Está técnica retira do conjunto de dados fornecido pelo pré-processamento as características dos dados que são relevantes. Na seleção retiram-se as características mais importantes do conjunto de características fornecido pelo processo de extração. No fim destes processos é obtido um conjunto de dados o mais compacto possível. Isto é feito para que não haja desperdício com processamento de informações desnecessárias.

Por fim a classificação associa cada padrão gerado pelos processamentos descritos anteriormente a uma classe. Esta fase é de suma importância para o sistema, pois um erro pode gerar muitos problemas em aplicações práticas. Existem dois principais grupos de métodos, os conexionistas e os estatísticos. De maneira geral, o método conexionista classifica o padrão baseado na representação interna dos padrões que passaram pelo sistema na fase de treinamento. Uma das técnicas de classificação utilizadas pelo método estatístico classifica o padrão baseada na probabilidade de um padrão pertencer a uma classe dado que este padrão possui algumas características.

Para a execução da tarefa de reconhecimento automático de alvos, pode haver a necessidade de combinar classificadores para melhorar o desempenho obtido. No próximo capítulo serão apresentados métodos para combinação de classificadores. 


\section{COMBINAÇÃO DE CLASSIFICADORES}

\section{1 - Introdução}

O cérebro humano é formado por um conjunto de neurônios de diferentes tipos, cada um com sua especialidade. A combinação destes diferentes tipos de neurônios é um dos aspectos responsáveis pelo desempenho apresentado pelo cérebro na realização de várias tarefas. Esta combinação tem grandes vantagens, principalmente em atividades que recebem informações provenientes de diferentes fontes (sinais visuais, auditivos, sensitivos e olfativos).

Suponha, por exemplo, um problema de classificação que envolva padrões formados por imagens, sons e odores. Uma pessoa cega leva desvantagem na classificação destes padrões, pois as imagens podem ter papel importante na classificação. Entretanto, em uma nova situação na qual apenas sons devem ser classificados, a mesma pessoa cega não terá problemas em classificá-los.

Desta forma, a combinação de classificadores deve ser direcionada ao problema em questão. Não há vantagens na combinação de classificadores para a solução de problemas bem resolvidos, ou seja, problemas para os quais já existe um classificador específico para solucioná-los satisfatoriamente.

A combinação de classificadores tem como objetivo resolver problemas mais gerais, problemas que envolvem diferentes tipos de dados. Além disso, pode-se aplicar a combinação em problemas que não foram resolvidos satisfatoriamente por um único classificador elou onde o desempenho apresentado pelo módulo de classificação deve ser estável. Entretanto, a combinação tem vantagens e desvantagens, como qualquer técnica. Portanto, deve-se analisar sua viabilidade para cada problema. 
Existe um número grande de justificativas possiveis para adotar uma abordagem baseada em combinação, ou modular para classificação. Uma delas é que a abordagem modular pode ser útil para resolver problemas que podem não ser satisfatoriamente resolvido utilizando um único classificador. Outra justificativa é que um sistema modular de classificadores pode explorar a capacidade especialista dos módulos, e conseqüentemente encontrar resultados que podem não ser obtidos por um único classificador [Sharkey, 96].

Uma conseqüência natural da exploração do potencial dos classificadores especialistas é considerar um sistema híbrido, onde os módulos especialistas não são necessariamente Redes Neurais, mas qualquer técnica indicada para o problema.

Provavelmente a razão mais comum para usar a abordagem modular está ligada ao propósito de melhorar a performance obtida. A obtenção de um melhor desempenho como resultado do uso da abordagem modular é confirmada por várias pesquisas [Sharkey, 97]. Recentemente foi observado que classificadores de diferentes tipos podem-se complementar [Ho, 94].

Finalmente, uma abordagem modular é provavelmente adotada quando existe interesse em uma maior plausibilidade neurobiológica e/ou psicológica, pois é razoável supor que em muitos aspectos do processamento de informações, realizado pelos seres humanos, está presente a modularidade.

\section{2 - Vantagens e desvantagens da combinação de classificadores}

Sem analisar a estrutura interna de um dado classificador e decidir sobre qual metodologia ele é baseado, pode-se simplesmente considerar um classificador como uma caixa funcional que recebe um padrão de entrada $\mathbf{x}$ e retorna uma classe $\mathbf{S}$, ou seja, $\mathbf{C}(\mathbf{x})=\mathbf{S}$. A Figura 5.1 ilustra a idéia de representação de um classificador por uma caixa funcional.

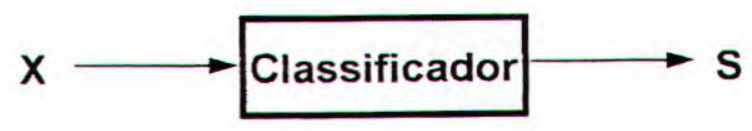

Figura 5.1 - Sistema simplificado de um classificador. 
Idealmente, a combinação de classificadores tem vantagens sobre o uso de um classificador individual, pois a classificação pode ser mais estável que aquela fornecida por um único classificador. Esta estabilidade tem origem na combinação, pois a combinação de várias decisões é geralmente mais estável, menos susceptível à oscilações, que apenas uma decisão.

A combinação deve exaltar as boas características de cada classificador e reprimir suas falhas, com isso a performance do sistema poderá ser melhor do que a performance de cada classificador individual utilizado no sistema.

A principal desvantagem da combinação de classificadores é o aumento da complexidade do problema. Quando apenas um classificador individual é utilizado, não é necessário se preocupar com a combinação das estruturas de classificação e/ou das saídas. Para resolver este problema, quando classificadores são combinados, utilizamse técnicas para particionar o problema entre os módulos da combinação [Ho, 94].

Um problema decorrente da combinação de classificadores é gerar a saída desta combinação, pois cada classificador individual $\mathbf{C}_{i}$ fornece uma saída $\mathbf{S}_{i}$ para o padrão $\mathbf{x}$, ou seja, $\mathbf{C}_{i}(\mathbf{x})=\mathbf{S}_{i}$. A principal dificuldade é a partir das saidas individuais $\mathbf{S}_{\mathbf{i}}$, que podem ser contraditórias, gerar uma única saída final. Desta forma, a combinação de decisões pode ter que lidar com decisões conflituosas. Este conflito de decisão traz um novo problema à classificação: escolher a decisão correta.

Um outro problema observado é a soma do erro da combinação, que não deve ser a soma dos erros de cada classificador do sistema. Quando os erros são somados, a combinação exalta o erro ao invés da boa performance. Na próxima seção serão discutidos os aspectos a serem considerados nas Redes Neurais para a função de classificadores.

\section{3 - Aspectos a serem considerados}

Pesquisas sobre combinação de classificadores em computação neural tiveram início por volta de 1965, com o trabalho desenvolvido por Nilsson [Nilsson, 65]. Além da combinação envolvendo Redes Neurais, várias outras áreas se interessaram pela combinação de classificadores, tais como: Aprendizado Simbólico de Máquina [Barnett, 81] e Engenharia de Software [knight, 86]. 
Em termos da computação neural, segundo [Sharkey, 96], a combinação envolve três aspectos principais:

1. A escolha de quantos classificadores serão combinados.

2. A criação ou seleção de um conjunto de classificadores para serem combinados.

3. O método pelo qual as saidas dos classifiçadores escolhidos serão combinadas.

A escolha de quantos classificadores serão combinados depende do problema em questão e do número de classes utilizadas. Uma sugestão intuitiva é usar um número de classificadores impar, de preferência um número primo. Desta forma ficará mais difícil a ocorrência de conflitos, onde duas classes distintas possuem o mesmo número de votos para serem selecionadas como a classe associada a um novo padrão.

Para que a combinação possa ser bem sucedida, é aconselhável utilizar diferentes modelos para classificadores. No caso do classificador ser uma Rede Neural é aconselhável utilizar redes com algoritmo de aprendizado diferentes e/ou modelos de redes diferentes, pois não existem vantagens claras em combinar redes idênticas.

Deve se destacar que a ênfase da combinação deve estar na exploração da similaridade ou da diferença na generalização de cada classificador participante do sistema. Da similaridade porque assim pode-se ter mais garantias que a decisão de um classificador foi correta. Da diferença porque, desta forma, padrões que foram classificados incorretamente por um classificador podem ser classificados corretamente por outro(s) classificador(es).

$\mathrm{Na}$ escolha dos classificadores que serão combinados, deve-se também levar em conta a capacidade de generalização e a dependência entre os classificadores do conjunto combinado. Classificadores que produzem muitos erros semelhantes não são recomendados para participar de uma mesma combinação, pois podem estar muito relacionados.

Quanto a escolha do método para combinar os classificadores, esta escolha depende do problema. Uma boa técnica é investigar mais de um método, selecionando o mais rápido e eficiente para o problema em questão.

As próximas seções apresentam métodos para a combinação de classificadores individuais. 


\section{4 - Niveis de combinação de classificadores}

A combinação de classificadores é uma abordagem modular de classificação, onde um conjunto de classificadores é combinado de alguma forma (em paralelo, em cascata, ou hierárquico) formando um módulo de classificação. Cada unidade do módulo é um classificador. Em um sistema mais sofisticado, módulos de classificadores pode ser combinados (mistura hierárquica de especialistas, por exemplo [Jordan, 94]). Nesse caso, cada unidade combinada é um módulo de classificação que pode ter vários classificadores internos. Na mistura hierárquica, os dados do problema são normalmente divididos entre os módulos, utilizando assim a técnica de dividir para conquistar.

\subsection{1 - Decompondo uma tarefa entre os módulos}

Para algumas aplicações, é possivel decompor um problema em subproblemas. Esta decomposição é possivel quando existe um número muito grande de padrões. As soluçöes para cada um dos subproblemas devem ser combinadas para que o problema original possa ser resolvido. Uma das principais dificuldades da utilização desta técnica está na decomposição dos problemas ou tarefas. A decomposição das tarefas pode ser tanto explícita como automática.

A decomposição explícita depende do entendimento da tarefa e das capacidades dos componentes da combinação. Essa decomposição fornece uma maneira de incorporar um conhecimento a priori na solução do problema. Por exemplo, a decomposição pode ser influenciada pela estrutura das tarefas, se os dados vêm de fontes diferentes ou possuem diferentes representações.

Em contraste, a decomposição automática é o resultado da aplicação de um algoritmo de partiçăo de dados. Esta técnica é usada particularmente quando o conhecimento específico das tarefas não está disponivel.

Há uma quantidade considerável de pesquisas sobre métodos de decomposição automática, entre os quais pode ser citado o método hierarchical mixture of experts [Jordan, 94]. Neste método, os dados de entrada são particionados em vários subespaços. Módulos do sistema são então treinados com dados locais convenientes. Isto acontece porque, segundo Sharkey [Sharkey, 97], o treinamento utilizando a 
partição dos dados é freqüentemente mais efetivo que o treinamento sobre todo o conjunto de dados.

\subsection{2 - Combinação de módulos}

Uma maneira pela qual uma abordagem de combinação pode ser caracterizada é em termos do relacionamento entre os módulos e a maneira pela qual eles se comunicam. O relacionamento entre os módulos pode ser caracterizado como sucessivo (ou em cascata), cooperativo (ou paralelo) ou supervisor (ou hierárquico) [Sharkey, 97].

Um relacionamento sucessivo entre os módulos envolve a decomposição de uma tarefa global em sucessivas tarefas, onde cada tarefa è atribuída a um módulo especialista. Muitos sistemas híbridos envolvem processos sucessivos, como sistemas nos quais um módulo é usado para pré-processar a entrada para um outro módulo. Similarmente, modelos cognitivos ou processos psicológicos provavelmente envolvem processos sucessivos, já que informações conflitantes são processadas em estágios no sistema nervoso [Sharkey, 97].

Um bom exemplo do modelo de relacionamento sucessivo é o modelo em cascata. Neste modelo a saída de um módulo, que não seja de saída, está ligada a entrada de um módulo posterior.

Um relacionamento cooperativo entre os módulos ocorre quando os classificadores do sistema unem-se para resolver a mesma tarefa. Por exemplo, na combinação em paralelo os classificadores podem possuir o mesmo conjunto de entradas e produzem saidas pertencentes ao mesmo conjunto de possíveis classes. Assim, todos os módulos estão cooperando para classificar um padrão de entrada.

No caso de Redes Neurais, a comunicação entre os módulos ocorre na entrada e/ou na saída, isto é, a saida de um módulo é usada como entrada de outro módulo. Contudo, existem também trabalhos sobre o potencial de comunicação entre os módulos baseado nas unidades escondidas, neste caso, a saída de uma unidade escondida de um módulo é usada como entrada para um outro módulo.

Um outro tipo de combinação é o relacionamento supervisionado entre os módulos está em McCormack [McCormack, 97]. Neste caso, um módulo de Redes Neurais é 
treinado para selecionar os parâmetros de uma segunda rede. Para tal, ele observa os efeitos de vários valores de parâmetros sobre o desempenho da rede supervisionada. Em um outro exemplo, uma rede suplementar foi treinada para predizer o erro da rede principal usando características da entrada e saida da rede principal [Sharkey, 97].

Um outro exemplo de relacionamento supervisor é o sistema mistura hierárquica de especialistas [Jordan, 94], onde uma rede gating determina o peso dado a resposta de cada módulo. Neste sistema, a rede gating funciona como supervisor, determinando qual módulo tem mais poder de voto.

Dentre os vários tipos de relacionamento entre os módulos de uma combinação, a combinação em paralelo, que se enquadra no relacionamento cooperativo, é de interesse para esse trabalho. A combinação em paralelo será apresentada de forma mais detalhada na próxima seção.

\section{5 - Combinação dos classificadores em paralelo}

Um método muito utilizado na combinação de classificadores é o de combinação em paralelo. Na combinação paralela, cada classificador possui sua própria entrada e saída, independente das entradas e saídas dos demais classificadores.

Na maioria dos problemas de combinação de classificadores o que se busca é uma única resposta ou saída. Para que a saída do sistema de combinação seja única, é necessário um método de combinação das saídas produzidas pelos classificadores individuais. Esse método de combinação só pode ser aplicado depois que todos os classificadores forneceram suas saídas.

O processo de combinação das saídas também pode ser chamado de processo de decisão. Esse processo integra os resultados de todos os classificadores gerando uma única saída. Se o processo de decisão for bem projetado, o sistema como um todo pode obter um desempenho superior àqueles obtidos por cada classificador individualmente.

Uma outra vantagem da combinação dos classificadores em paralelo é que ela pode ser implementada em um processador paralelo, levando a um bom desempenho com relação ao tempo de processamento. No modelo em paralelo, pode ser realizado um treinamento independente para cada classificador, unindo as saidas dos 
classificadores apenas na fase de classificação. A estrutura em paralelo é apresentada na Figura 5.2.

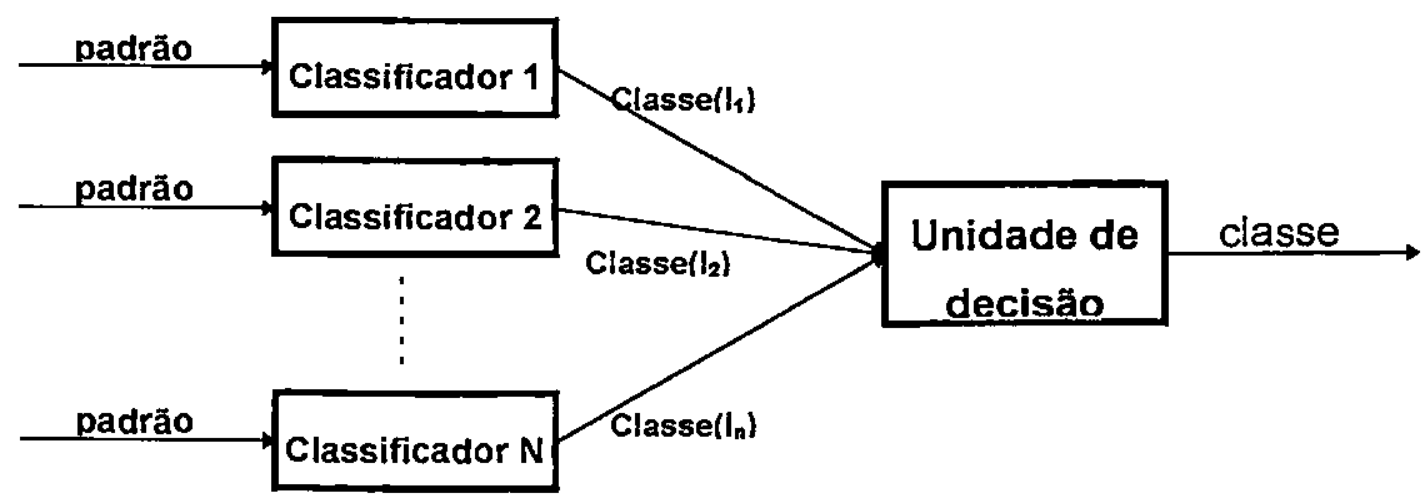

Figura 5.2 - Estrutura de combinação do modelo em paralelo.

$\mathrm{Na}$ combinação em paralelo podem ser variados diversos aspectos, como por exemplo, o conjunto de entrada de cada classificador e o método de combinação das saídas.

\subsection{1 - Definição do conjunto dos dados de entrada}

O conjunto de dados de entrada pode ser dividido ou não dependendo da complexidade do problema envolvido e da quantidade de padrões de treinamento. Em um problema que envolva um grande número de padrōes, pode haver a necessidade de dividir o conjunto para obter classificadores especializados em determinadas classes do problema. Assim, o sistema é simplificado, pois cada classificador individual requer uma estrutura mais simples já que pode receber menos padrōes de treinamento. Diversos métodos de divisão de conjunto são utilizados em estruturas de combinação paralelas.

\subsubsection{1 - Um único conjunto de entrada}

Este método de divisão explora a capacidade dos classificadores envolvidos no sistema. Cada classificador recebe o mesmo conjunto de entrada. O objetivo é que 
cada classificador venha a suprir as falhas dos outros classificadores do sistema, obtendo assim um melhor desempenho global.

Como um exemplo, suponha que para um problema com duas classes existe um sistema com cinco classificadores. Suponha também que dentre estes classificadores, três são sempre bons classificadores para a mesma classe. Para a classe A os classificadores 1,2 e 3 são bons e os 4 e 5 são ruins. Para a classe B os classificadores 1,3 e 4 são bons e os 2 e 5 são ruins. Assim, cada classe sempre terá 3 classificadores com boa performance. A utilização do método de combinação de saídas com pesos iguais levará a uma classificação global melhor. A dificuldade deste método está na escolha dos classificadores, pois combinar classificadores com falhas semelhantes não otimiza o resultado produzido pelo sistema.

\subsubsection{2 - Particionando o conjunto original em subconjuntos de amostras}

Uma boa técnica para melhorar o processo de treinamento do sistema de combinação é dividir o conjunto de dados em subconjuntos de padrōes. Uma vantagem desta divisāo é a introdução de independência da amostra. A independência da amostra ocorre quando é possivel afirmar que o resultado da rede independe dos dados utilizados no treinamento do sistema, ou seja, em qualquer amostra escolhida aleatoriamente do conjunto de padrões, o resultado da rede será aproximadamente o mesmo.

Uma prática comum para a criação de subconjuntos de treinamento é utilizar técnicas de amostragens. Dentre os métodos usados para amostragem de dados, podem ser citados o cross validation e o bootstrapping. Embora esses métodos são muito utilizados na estatística e em aprendizado de máquina como técnicas para estimação de erro, também podem ser utilizados como sistemas de divisāo de conjuntos.

- Cross-Validation: O método cross-validation também é conhecido como $k$-fold cross-validation, onde $\mathbf{k}$ representa o número de partições geradas aleatoriamente. A amostra de exemplos é divida em $\mathbf{k}$ partiçōes mutuamente exclusivas. A cada iteração, k-1 partições são utilizadas para treinar o sistema e a outra partição restante é usada para testar o sistema de aprendizado. 
- Bootstraping: Este método é mais utilizado com pequenas amostras. Tradicionalmente são consideradas pequenas amostras aquelas que possuem 30 ou menos padrões. Existem vários métodos bootstrap, mas o escolhido para ser descrito aqui é o e 0 bootstrap. Para esse método, o conjunto de treinamento consiste de $\mathbf{n}$ casos amostrados com substituição a partir de uma amostra de tamanho $\mathbf{n}$. Amostrados com substituição significa que os exemplos de treinamento são retirados do conjunto inicial de exemplos, mas cópias dos elementos retirados podem permanecer no conjunto inicial, de forma que elementos repetidos podem ser amostrados.

Outros métodos de divisão de conjunto de entrada:

- Origem de dados diferentes: Este método faz uso de entradas de diferentes origens. Isto é possivel quando mais de um sensor é usado para a entrada de dados. Este método é aplicável quando os sensores são projetados para coletar diferentes tipos de informação.

- Pré-processamento: Os dados sobre os quais as redes são treinadas podem ser modificados utilizando diferentes métodos de pré-processamento. Por exemplo, diferentes conjuntos de características podem ser extraídas dos dados originais. Alternativamente, os dados de entrada para o conjunto de redes podem ser distorcidos de diferentes maneiras; por exemplo, pela injeção de ruído ou pelo uso de transformações não lineares nos dados de treinamento, teste e validação.

Além dos métodos de divisão do conjunto de dados, existem métodos de combinação das saídas dos classificadores. Os dois métodos podem ser combinados de diversas formas, dependendo do tipo de problema. Os métodos de combinação de saídas dos classificadores serão analisados na próxima seção.

\subsection{2 - Combinação das saídas dos classificadores combinados em paralelo}

Um aspecto importante na combinação de classificadores está na combinação de suas saídas. A grande dificuldade é combinar as saídas de forma que erros de alguns classificadores não influenciem a resposta correta de outros. Caso exista um classificador que forneceu a resposta correta, então todo o sistema deve fornecer a resposta correta; porém ainda não existe método que garanta esta situaçăo. 
Uma das maneiras de classificar os modelos de combinação é analisar se no modelo existe retreinamento ou não. Existe retreinamento quando o sistema de combinação das saídas utiliza os dados de entrada ou as saídas dos classificadores para seu próprio treinamento. Além disso, quando o sistema de combinação é supervisionado, este sistema também utiliza as saídas desejadas para o seu treinamento.

O modelo não possui retreinamento quando não há nenhuma fase de treinamento no sistema de combinação das saídas.

Esta parte do sistema tem forte influência no desempenho obtido, pois uma combinação infeliz das saídas pode destruir todo o trabalho anterior dos classificadores individuais. A seguir serão apresentadas técnicas para combinação das saidas.

\subsubsection{1 - Decisão aleatória}

No sistema de decisão aleatória, após todos os classificadores fornecerem suas respostas, a resposta de um dos classificadores é escolhida aleatoriamente. Essa reposta representará a decisão do sistema de combinação.

Esse método é utilizado para medir a eficiência dos outros métodos de combinação das saídas (neste método não há retreinamento). Para medir esta eficiência, aplica-se - método de decisão aleatória e obtém-se uma medida de performance. Essa performance é comparada com a performance de um outro método de combinação que se deseja avaliar. Dependendo do tempo de processamento deste outro método e de seu desempenho em comparação à decisão aleatória, é dada uma pontuação à sua eficiência.

\subsubsection{2 - Decisão pela Combinação linear das saídas}

Nessa abordagem, a saída final do sistema é uma combinação linear das saídas produzidas por cada classificador individual. Um método muito conhecido pertencente a abordagem é a decisão pela maioria. Nesse método, cada classificador tem o poder de decisão igual aos demais. Assim, um padrão de teste é atribuido a uma classe quando a soma dos votos dos classificadores para esta classe representa a maioria 
dos votos, ou seja, a classe for eleita pela maioria dos classificadores como a classe a qual pertence o padrão de entrada.

A vantagem deste sistema é que todas as decisões têm o mesmo peso e um erro de decisão só é válido quando for um erro da maioria, ou seja, para o sistema errar a maioria dos classificadores devem errar. Para melhorar a confiabilidade do sistema, pode-se atribuir ao método um threshold de, por exemplo, $51 \%$. Se mais da metade dos classificadores determinar que o novo padrão pertence a uma classe, então o novo padrão é atribuido a esta classe, caso contrário, o novo padrão é considerado desconhecido.

Outro método pertencente a esta abordagem é a decisão em hierarquia. Nesse método cada classificador possui um poder de voto diferenciado, sendo atribuído um peso ao seu voto.

Nos métodos de combinação pela maioria e em hierarquia não há retreinamento, mas existem outros modelos de combinação linear que utilizam retreinamento. Um exemplo de combinação linear com retreinamento é a utilização da rede Perceptron. para fazer a combinação.

\subsubsection{3 - Decisão pela Combinação não linear das saidas}

Esta abordagem é muito semelhante à combinação linear, no entanto, para efetuar a combinação é utilizado uma função não linear. Essa função pode ser estatística, lógica ou implementada por um classificador final de combinação. Nesses modelos, como no caso do linear, pode haver retreinamento ou não, dependendo do método utilizado.

No caso da combinação ser realizada por um classificador final, esse classificador tem sua entrada formada pela união das saidas dos classificadores individuais. Nesta forma de combinação, os classificadores combinados trabalham como "filtros de erros", facilitando assim a classificação feita pelo classificador final que combinará as saidas. 


\section{6 - Estrutura Seqüencial ou em Cascata}

No sistema em cascata, o resultado da classificação fornecida por um classificador é usado para direcionar o processo de classificação do classificador seguinte. 0 problema com este tipo de estrutura é que o erro de um classificador é propagado para todos os classificadores posteriores. Assim, o erro total do sistema é a acumulação dos erros dos classificadores individuais participantes do mesmo.

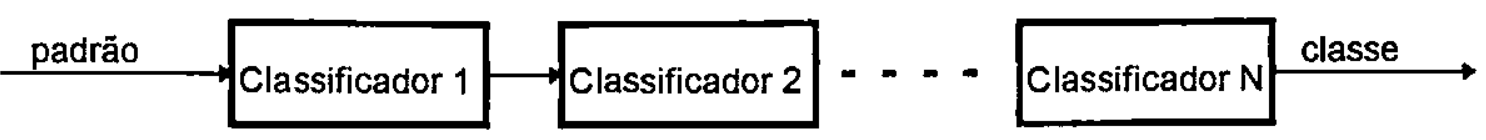

Figura 5.3 - Modelo do sistema em cascata.

Uma vantagem deste modelo é que ele não necessita de nenhum método para a combinação das saídas, pois o modelo fornece apenas uma saída para cada padrão de entrada. Neste modelo, cada classificador pode ser pensado como uma camada de neurônios em uma Rede Neural Multicamadas. A Figura 5.3 ilustra o sistema em cascata.

\section{7 - Estrutura Hierárquica}

O modelo hierárquico é uma mistura dos modelos em paralelo e em cascata. Neste modelo, alguns dos classificadores são combinados em paralelo, enquanto os outros são combinados em cascata.

O exemplo apresentado na Figura 5.4 é apenas uma maneira de combinar os modelos em cascata e em paralelo. Diversas outras combinações são possiveis, de acordo com o problema em questão. 


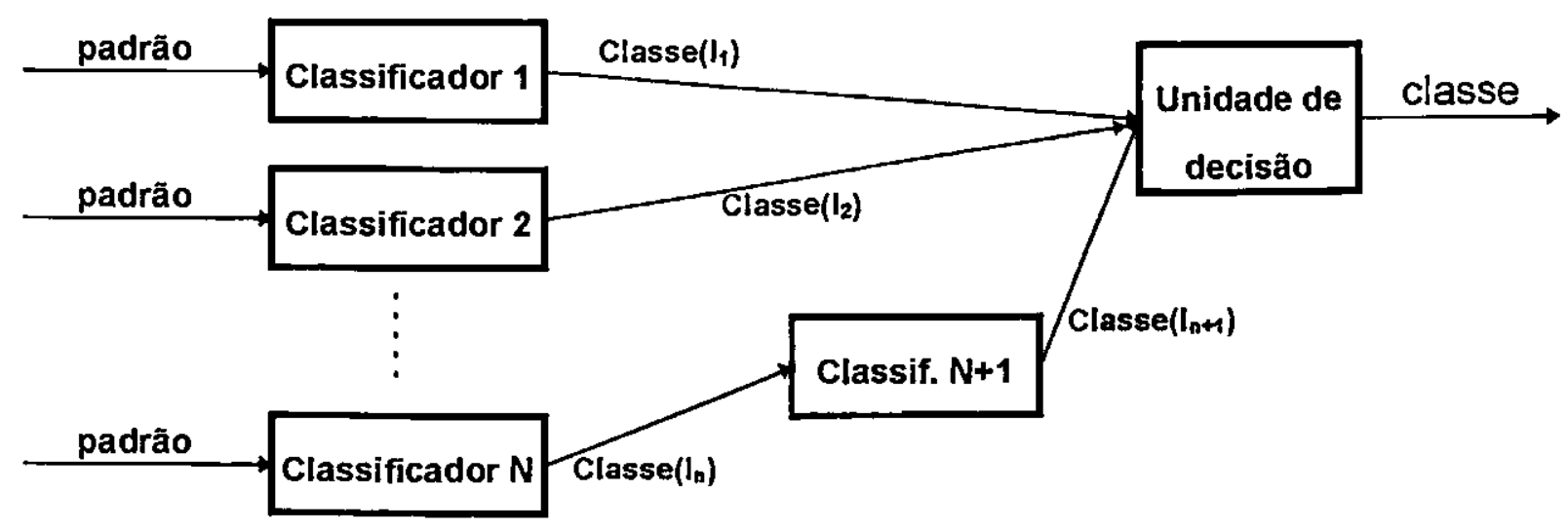

Figura 5.4 - Modelo do sistema hierárquico.

\section{8 - Trabalhos Variados}

Diversas técnicas têm sido propostas para o uso de diferentes tipos de classificadores simultaneamente. A seguir serão apresentados de forma sucinta alguns trabalhos sobre combinação de classificadores.

$\mathrm{Em}[\mathrm{Lu}, 96]$ foi realizada uma combinação utilizando três classificadores diferentes: Rede Neural, Comparação de Estruturas (structural template matching) e Classificador Polinomial. Os dados utilizados foram imagens de números escritos à mão provenientes de envelopes do correio. Cada classificador gerou uma lista de hipóteses com niveis de confidencia para cada padrão de entrada. O resultado de cada classificador foi uma tabela de função de densidade de probabilidade. Para a combinação dos classificadores foi utilizado um método bayesiano que processava as tabelas geradas pelos classificadores. A função da combinação foi responsável pela união dos espaços de padrões de cada classificador.

Uma outra combinação, encontrada em [Ho, 94], utilizou quatro tipos de classificadores: Reconhecimento de Caracteres e Postprocessing, Método baseado na segmentação, Formato de palavras por características de traço e Formato de palavras por características "Baird". Os dados utilizados foram imagens de 1365 palavras da língua inglesa. Os métodos de combinação utilizados foram: Combinação pela Votação, Combinação por um modelo de regressão estatística, Combinação pelo método Borda, Combinação por um modelo de seleção dinâmica e Oracle. 
Trabalhos realizados por [Chuanyi, 97] foram combinadas vários classificadores entre os classificadores estão varias Redes Neurais. No artigo não está claro quantos classificadores foram utilizados. As bases de dados utilizadas foram: base de cartões de credito Card1, base Diabetes1, Gene1 (base sobre a seqüência do DNA) e base de imagens de números escritos à mão. O método de combinação utilizado foi a combinação pela maioria, este método combinou apenas Redes Neurais. O método $\mathrm{K}$ vizinhos mais próximos também foi utilizado para comparação com o resultado da combinação.

Em um outro artigo $[X u, 92]$ foram utilizados quatro classificadores. Os classificadores não foram descritos porque o enfoque do artigo está na combinação. $A$ base de dados utilizada foi a de imagens de números escritos à mão. Os métodos de combinação utilizados foram: Combinação baseada no formalismo de Dempster Shafer, Combinação baseada no formalismo Bayesiano e Combinação pela Maioria.

Todos os métodos de combinação utilizados nos artigos citados acima podem ser classificadas entre os métodos de combinação descritos neste capítulo. Por exemplo, a combinação baseada no formalismo de Dempster-Shafer é um método de combinação em paralelo que possui combinação não linear das saídas. A seguir será apresentado um outro estudo de casos envolvendo uma combinação mais sofisticada.

\section{9 - Mistura hierárquica de especialistas}

O método de mistura hierárquica de especialistas, proposto por Michael Jordan [Jordan, 94], utiliza uma arquitetura composta de $\mathrm{N}$ módulos. Os módulos possuem um conjunto de $M$ redes especialistas, que já foram treinadas com o seu conjunto de dados, e uma rede gating, que associa um peso à saída produzida por cada uma das redes especialistas.

A decisão de cada módulo é definida pelo somatório das saida ponderadas de cada rede especialista. No caso do modelo possuir dois niveis, um peso gerado por uma outra rede gating é associada à decisão de cada módulo e a saída do sistema também é definida pelo somatório das saídas ponderadas de cada módulo.

A arquitetura mistura hierárquica de especialista (Hierarchical Mixture-of-Experts, $\mathrm{HME}$ ) está ilustrada na Figura 5.5. Note que a figura mostra uma arquitetura de dois 
níveis, mas existe a possibilidade de variar o número de níveis. Essa arquitetura é uma árvore na qual redes gating, ou redes auxiliares, são nós não terminais da árvore e os módulos especialista são os nós terminais.

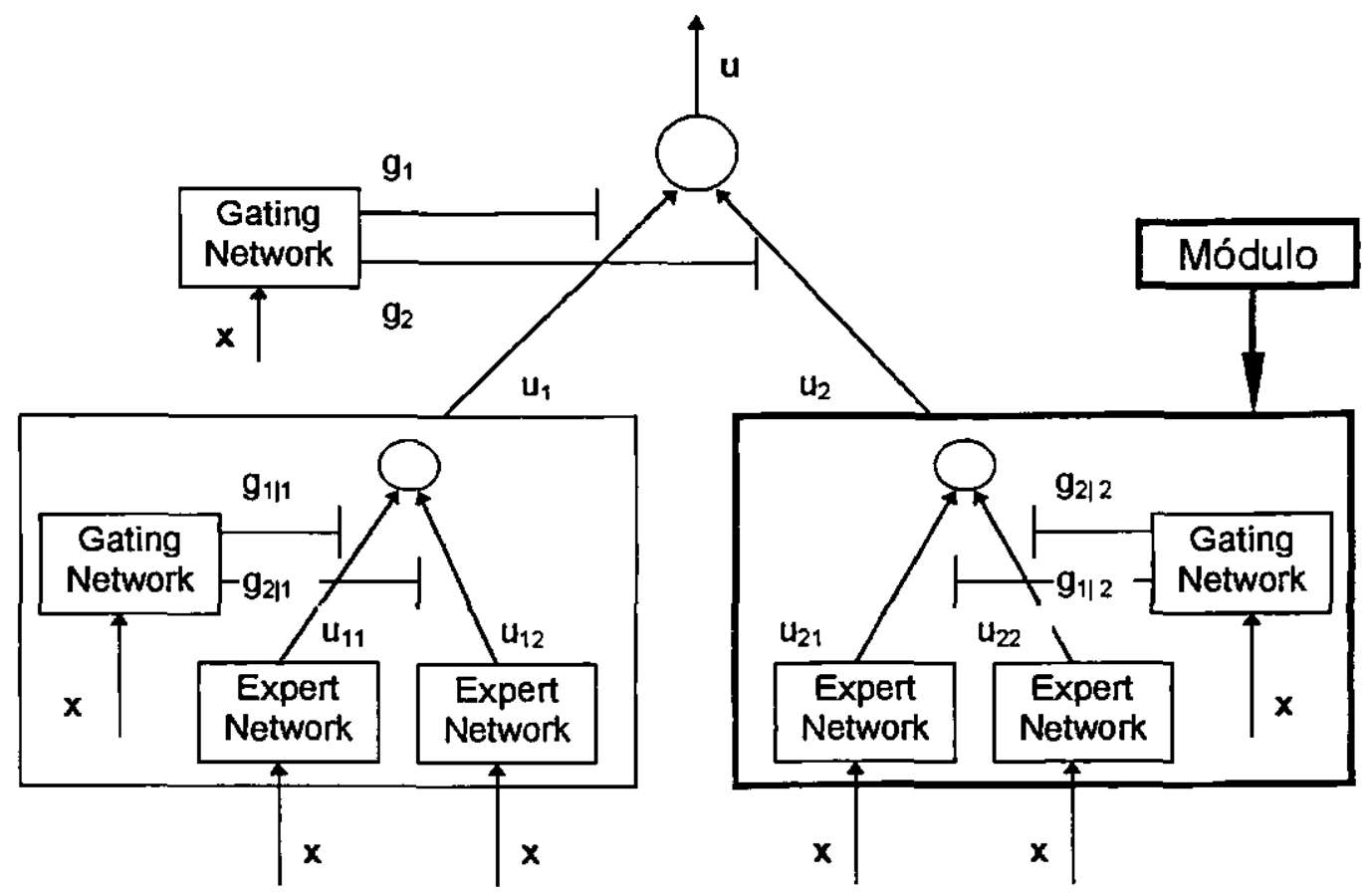

Figura 5.5 - Mistura hierárquica de especialista em dois niveis.

A mistura hierárquica de especialistas também utiliza a técnica de dividir para conquistar na partilha dos dados do problema. A partir do conjunto total de dados são gerados subconjuntos de padrões ou exemplos, onde cada subconjunto é atribuído a um dos $\mathbf{N}$ módulos do sistema. Dentro de cada módulo, o subconjunto recebido também é particionado entre as $M$ redes especialistas pertencentes ao módulo. Assim, os dados do problema são divididos entre os módulos, que por sua vez dividem o subproblema recebido entre as suas redes especialistas. Esta divisão está ilustrada na Figura 5.6. 


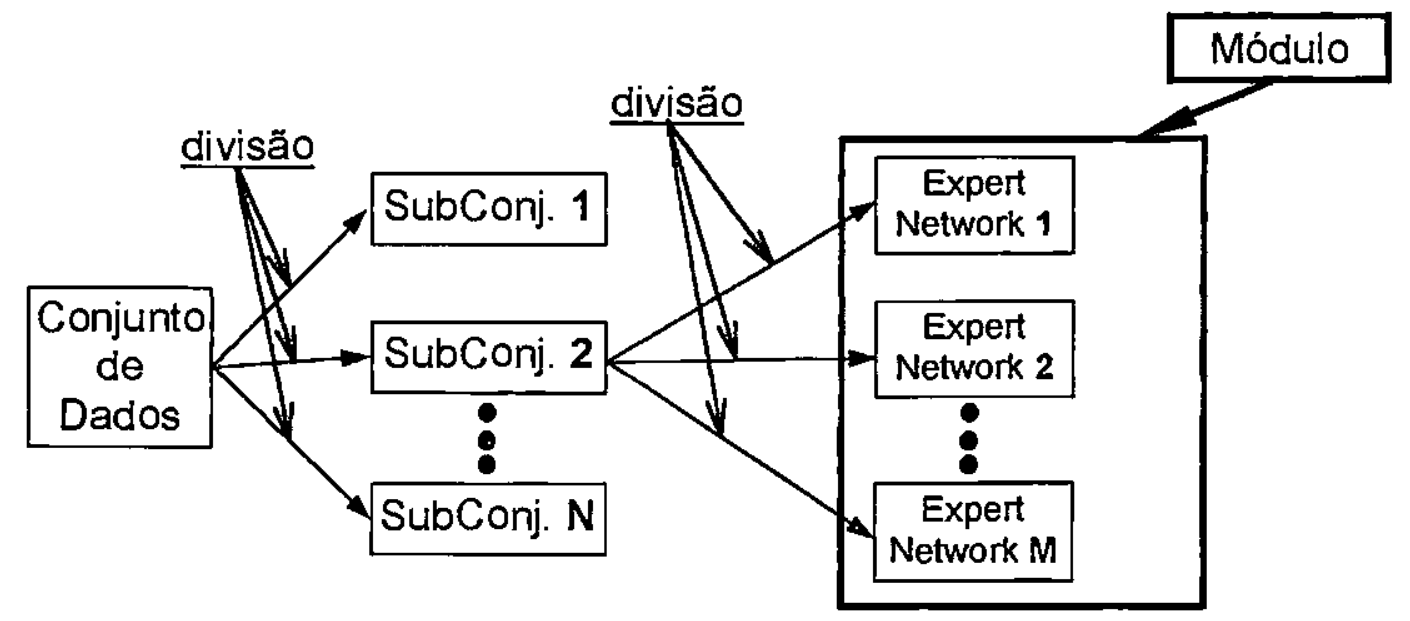

Figura 5.6 - Divisão do conjunto de dados no sistema HME.

$\mathrm{Na}$ divisão do conjunto de dados do problema, mais de um subconjunto pode conter o mesmo padrão. Isso pode acontecer porque as regiōes têm fronteiras fuzzy, o que significa que os dados podem estar simultaneamente em mais de uma região.

Depois do conjunto de dados ser dividido e as redes especialistas estiverem treinadas, é necessário saber quais os possiveis subconjuntos de um novo padrão. $A$ informação de quais subconjuntos possuem padrōes mais similares ao novo padrão é utilizada quando a rede gating for determinar os pesos de cada rede especialista. Esta informação é importante, pois quanto mais semelhante ao novo padrão forem os padrőes utilizados no treinamento de uma rede especialista, maior será o peso dessa rede especialista. Esta distribuiçăo de pesos também acontece na saída do módulo. Da mesma forma que acontece para a saída da rede especialista, porém em um nível diferente.

Interpretando probabilisticamente, a rede gating funciona como um classificador que mapeia um padrão de entrada $x$ na probabilidade de geraçăo da saída desejável pelos vários especialistas.

Todas as redes especialistas da árvore são lineares. Estas redes também são chamadas de "generalizadores lineares", segundo a terminologia utilizada na Estatística. 


\subsection{1 - Algoritmo de treinamento para a arquitetura HME}

Existe um algoritmo de treinamento para a arquitetura $H M E$, baseado na estrutura de maximização da expectativa (Expectation-Maximization, EM) [Jordan, 94]. O algoritmo EM é uma técnica para lidar com problemas de estimação de probabilidade máxima. Na prática, EM tem sido aplicado quase exclusivamente em problemas de aprendizado não-supervisionado.

$\mathrm{Na}$ literatura de Redes Neurais e de Aprendizado de Máquina, EM aparece no contexto de clustering [Jordan, 94]. Esse algoritmo é uma alternativa para métodos de gradiente. Ele é particularmente usado para modelos nos quais as redes especialistas e redes gating possuem formas paramétricas simples.

O EM é uma abordagem iterativa para estimação da probabilidade máxima. Cada iteração do algoritmo EM é composta de dois passos: um passo de estimação $(E)$ e um passo de maximização (M). O passo $\mathrm{E}$ é composto por uma propagação ascendente e descendente na árvore, que calculam a probabilidade a posteriori, realizando assim a estimação. $O$ passo $M$ realiza a maximização de uma função de probabilidade que é redefinida em cada iteração do passo $\mathrm{E}$.

Jordan et al [Jordan, 94] testaram este algoritmo para um problema de identificação de sistema näo linear. Os autores relataram que o algoritmo convergiu rapidamente, convergiu próximo de duas ordens de magnitude mais rápido que a rede MLP utilizando o algoritmo backpropagation.

Para obter o algoritmo EM ou para maiores detalhes, uma boa referencia é [Jordan, 94]. Neste artigo o autor descreve detalhadamente o algoritmo e algumas de suas variações.

\subsection{0 - Método de combinaçäo proposto}

Uma estratégia alternativa para combinar classificadores seria a utilização de um sistema de combinação que dê mais crédito (maior peso) aos classificadores com maior confiança (maior tendência nítida para a classe escolhida) na sua classificação. Desta forma, cada classificador terá seu peso na decisão final ponderando de acordo com a sua confiança de classificação. Além disso, se o peso do classificador for variável para cada classe em função da resposta dada por ele para cada padrão, 
então o sistema de combinação estará sempre relacionando um novo padrão à classe que possui a maior confiança. Esse método proposto de combinação tenta utilizar estas estratégias como base.

Porém, classificar com maior confiança, neste sistema, não significa maior corretude de classificação, pois um classificador poderá classificar um padrão incorretamente com alto grau de confiança. Como existem pessoas com muita certeza de uma informação errada, pode também haver um classificador análogo. Neste caso, o problema não está na combinação, mas no classificador.

Esse método utiliza a representação gerada pelo classificador da classe para realizar a combinação, e não somente o fato do padrão pertencer a uma classe ou outra, como faz a maioria dos outros métodos de combinação. Além disso, neste método não há a necessidade de retreinamento. O combinador não tem contato com a saída desejada.

Esse combinador, chamado de "Soma Máxima", faz uma soma das saidas dos classificadores e uma busca pelo maior elemento no vetor de saída da combinação, o maior elemento é igualado a 1 e os demais a 0 . Para que isso possa ocorrer é fundamental a utilização de uma representação das classes. Essa representação é sinalizada por bits, contendo 1 ou 0 , dependendo da classe que a saída do classificador representada. Por exemplo, suponha um sistema com 4 classes. A saída de cada classificador deverá conter 4 neurônios. A classe 1 será representada por 0001, a classe 2 por 0010, a classe três por 0100, e a classe 4 por 1000. Para um maior número de classes basta aumentar o número de saída dos classificadores participantes do sistema.

As Redes Neurais de combinação não aprenderam este método, provavelmente porque o método proposto realiza duas tarefas distintas, soma e a busca pelo maior elemento. A busca pelo maior elemento por se tratar de uma operação de alto nível, difícil de ser aprendida por uma Rede Neural. Além disso, se a rede aprender a realizar esta tarefa certamente utilizará um tempo muito maior do que o tempo gasto pelo método proposto.

Como exemplo do funcionamento do método de combinação, suponha um sistema de combinação com duas classes, portanto cada classificador terá 2 saídas. Neste 
sistema participarão 3 classificadores. Cada saída de um classificador é um número real variando entre 0 e 1.

Para um único novo padrão a saída do classificador 1 foi 0.10 .8 ; a saída do classificador 2 foi 0.70 .6 ; a saída do classificador 3 foi 0.40 .9 , somando as saídas termos 1.22 .3 , o maior elemento do vetor é o 2.3, portanto à saída do sistema de combinação será 0 1. Classificando desta forma o novo padrăo como pertencente à classe número 1. Perceba que método de combinação, classifica o padrão na classe com maior confiança.

Analisando o sistema de combinação, percebe-se as seguintes vantagens:

- Neste sistema, as próprias saídas dos classificadores já atribuem pesos as suas decisões.

- Se um classificador possui uma decisăo muito forte para uma classe, o sistema de classificação dá um credito alto a este classificador. Se esse classificador estiver errado, o problema não está na combinação, mas no classificador que atribui o novo padrão com grande certeza a uma classe errada.

- Não há retreinamento, o que dá agilidade à combinação.

- O sistema é simples e fácil de ser aplicado.

Esse sistema de combinação enfoca o problema de combinação com uma abordagem diferente. Nesta abordagem, a representaçăo das classes geradas pelos classificadores é explorada para uma melhor combinação. No capítulo de experimentos é apresentado uma comparação dos resultados obtidos com esse método com os resultados de outros métodos de combinação.

\subsection{1 - Conclusão}

Neste capítulo foram analisados os aspectos envolvidos na combinação de classificadores. A combinação de classificadores tem um respaldo biológico, pois está fortemente presente no cérebro humano, que é a principal fonte de inspiração para os modelos conexionistas.

A principal vantagem da combinação é a união de diferentes modelos de classificação na solução de um mesmo problema. Tem sido observado que alguns 
classificadores complementam a performance de outros. A principal desvantagem é o aumento de processamento. A combinação também traz o problema da união estrutural dos classificadores e da combinação de suas saídas.

Diversos métodos foram criados para unir os classificadores estruturalmente. Um deles propõe a união em paralelo, no qual cada classificador é treinado independentemente dos demais. A outra proposta é a combinação em cascata, na qual a saída de um classificador serve de entrada para o classificador seguinte. Uma terceira proposta é a estrutura hierárquica, que une os métodos anteriores. Finalmente, foi apresentado o método de mistura hierárquica de especialistas, onde vários especialistas fornecem suas saidas e a essas saídas são associados pesos fornecidos por uma rede auxiliar. Essa rede auxiliar determina a relevância da saída de cada especialista em função da entrada.

Para o problema de combinação das saídas existem vários métodos. Estes métodos são direcionados para a estrutura em paralelo ou hierárquica. Existem métodos de combinação lineares, não lineares e aleatórios.

Além desses métodos foi proposto um novo método de combinação que utiliza a representação das classes para determinar o peso de resposta de cada classificador. No próximo capítulo serão comparados os desempenhos dos métodos de combinação apresentados neste capitulo. 


\section{EXPERIMENTOS}

\section{1 - Introdução}

Neste capitulo, será investigado o desempenho dos métodos de combinação de classificadores discutidos neste trabalho. Para a aplicação desses métodos de combinação foram utilizadas três Redes Neurais: Radial Basis Function [Beale, 94], Cascade Correlation [FahIman, 90] e Multi-Layer Perceptron [Rumelhart, 86]. Para o treinamento das redes Cascade Correlation e Multi-Layer Perceptron foi utilizado o simulador de redes neurais SNNS versão 4.1 , os algoritmos utilizados para o treinamento foram os algoritmos padrão (CC e Backpropagation padrão respectivamente). No caso da rede RBF, o algoritmo utilizado foi o de decomposição em valores singulares (Singular Value Decomposition, SVD). O método SVD é baseado em um método homônimo para calcular uma matriz pseudo inversa [Press, 88].

Essas Redes Neurais foram aplicadas sobre três bases de dados: Silhuetas de Veículos, Imagens de Navios da Marinha Americana e Imagens de Navios da Marinha Brasileira. Para a realização dos experimentos, cada base de dados foi dividida em três grupos de dados experimentais. Todos os três grupos possuíam os mesmos padrões, a única diferença entre os grupos está na ordem em que os padrões se encontravam. Isso aconteceu porque os grupos foram embaralhados aleatoriamente.

Em cada grupo os dados foram divididos em três subgrupos: Treinamento, Validação e Teste. Em um grupo, padrões que foram utilizados para treinar poderiam ser utilizados em um outro grupo para testar ou validar, e vice versa. Os resultados apresentados nas tabelas deste capítulo são a média dos resultados produzidos pelos três grupos na fase de treinamento, validação e teste. Esses resultados estão apresentados em porcentagens. 
O conjunto de treinamento ficou com $50 \%$ dos padrões do conjunto total de dados, a validação com $25 \%$ e o teste com os $25 \%$ restantes. A aleatoriedade imposta na divisão dos dados dá maior credibilidade aos resultados obtidos nos experimentos, pois os resultados tornam-se mais independentes dos dados utilizados nas fases de validação, treinamento e teste.

\section{2 - Métodos de Combinação}

Os métodos de combinação foram aplicados nas saídas de três Redes Neurais utilizadas nesta Tese: Radial Basis Function, Cascade Correlation e Multi-Layer Perceptron. Para o treinamento das Redes Neurais, foram utilizados métodos supervisionados, pois os dados possibilitavam este tipo de treinamento. As unidades de saída dessas Redes Neurais produziam valores reais variando no intervalo de 0 a 1. A saída desejada para cada unidade de saída era 0 ou 1. Cada unidade de saída dessas redes foi associada a uma dada classe. Se o problema possuísse quatro classes, cada rede teria quatro unidades de saída.

Os métodos de combinação utilizados neste trabalho estão descritos rapidamente nas subseções a seguir, pois já foram descritos de maneira mais genérica no capítulo de Combinação de Classificadores. Todos os métodos de combinação utilizam a distribuição dos classificadores em paralelo, pois desta forma os classificadores cooperam entre si para a resolução de um mesmo problema. Assim, todos os classificadores utilizam os mesmos conjuntos de treinamento, validação e teste.

\subsection{1 - Combinação pela Votação}

No método de combinação pela votação cada classificador do sistema de combinação sugere uma classe para o padrão desconhecido. 0 método de combinação apenas verifica qual classe foi indicada mais vezes e atribui o padrão desconhecido a esta classe. 


\subsection{2 - Combinação pela Soma Máxima}

Este método de classificação foi proposto $\theta$ desenvolvido neste trabalho para classificadores que possuem saídas com valores reais. Nestes classificadores, cada unidade de saída representa a probabilidade do padrão desconhecido pertencer a uma classe. Quanto maior o valor da unidade de saída, maior a probabilidade do padrão desconhecido pertencer a classe representada por esta unidade. Normalmente as saídas das unidades variam de 0 a 1.

Este método de combinação soma os valores das unidades de saída que representam a mesma classe em cada classificador. Depois compara os resultados desta soma para cada classe. A classe que obter a maior soma é a classe eleita para representar o padrão desconhecido.

\subsection{3 - Combinação pela Média}

Neste método de combinação, as saídas dos classificadores são somadas $\theta$ divididas pelo número de classificadores do sistema de combinação. A soma depende do número de unidades de saída. Se cada classificador possuir quatro unidades de saida, o resultado da combinação também possuirá quatro unidades de saída. A soma é feita pelas unidades de saída, ou seja, as unidades de saída 1 de todos os classificadores são somadas e a média é calculada. O mesmo é feito para as unidades de saída 2, 3, até $\mathrm{N}$.

Este método apenas calcula a média das saídas dos classificadores. A resposta do método de combinação é a média das respostas dos classificadores individuais.

\subsection{4 - Combinação pela Média Ponderada 321}

Este método utiliza a média das saídas dos classificadores do sistema de combinação do mesmo modo que o método anterior. A diferença é que cada classificador tem um peso de voto. No caso de utilizar apenas 3 classificadores, como é o problema tratado neste texto, o primelro classificador tem peso 3 o segundo tem peso 2 e o terceiro tem peso 1. O peso é atribuído ao classificador em função do erro cometido pelo classificador na fase de teste, quanto menor o erro maior o peso. 


\subsection{5 - Combinação por Redes Neurais}

Este método de combinação utiliza as saídas dos classificadores do sistema de combinação para gerar um arquivo de treinamento para uma Rede Neural de combinação, aqui chamada de rede juiz. Esta técnica de treinar o método de combinação é chamada de retreinamento. $O$ arquivo de treinamento do método de combinação é gerado com as saídas obtidas do arquivo de treinamento dos classificadores individuais, ou seja, a saídas geradas por cada classificador para os dados de treinamento, após os classificadores individuais terem sido treinados, é utilizada para treinar o sistema de combinação. Da mesma forma são gerados os arquivos de validação e teste.

$\mathrm{Na}$ rede de combinação, o número de unidades de entrada é igual ao número de classificadores multiplicado pelo número de unidades de saída de cada classificador. O número de saídas da rede é igual ao número de unidades de saída de cada classificador. O número de unidades intermediárias varia de acordo com 0 desempenho da rede para o problema.

A rede é treinada com o arquivo gerado com as saídas dos classificadores na fase de treinamento. Se os classificadores forem supervisionados então a rede de combinação também será supervisionada. Nesta Tese as redes de combinação foram supervisionadas. Foram utilizados dois modelos de redes neurais para a combinação:

- Muti-Layer Perceptron: a rede foi treinada com o algoritmo Standard Backpropagation para a combinação dos classificadores.

- Radial Basis Function: a rede foi treinada com o algoritmo SVD.

Na próxima seção será descrito os experimentos realizados nas base de dados de Silhueta de Veículos.

\section{3 - Experimentos com dados de Veículos}

O primeiro grupo de experimentos utilizou uma base de dados de silhuetas de veículos. Este conjunto de dados é proveniente do Turing Institute em Glasgow, Escócia. Cada um dos dados é formado por 18 características extraídas de imagens 
de silhuetas de veículos. Os dados estão distribuídos em 4 classes para classificação. Esta base de dados possui 946 padrões.

Todas as redes utilizadas como classificadores nesta base de dados possuíam 18 entradas e 4 saídas. A rede Cascade Correlation, após o treinamento ficou com 160 neurônios intermediários. O número máximo de ciclos utilizados foi 2000.

A Tabela 6.1 apresenta os resultados obtidos pela rede Cascade Correlation nas fases de treinamento, validação e teste. Esses resultados não foram bons, provavelmente por problemas apresentados no algoritmo do simulador SNNS.

\begin{tabular}{|l|c|c|c||}
\hline CASCADE CORRELATION & TREINAMENTO & VALIDAÇÃO & TESTE \\
\hline Errado & 4,49 & 5,84 & 4,87 \\
\hline Certo & 66,66 & 63,82 & 70,28 \\
\hline Desconhecido & 28,84 & 30,33 & 24,84 \\
\hline
\end{tabular}

Tabela 6.1 - Resultado da rede Cascade Correlation.

A rede RBF ficou com 165 unidades intermediárias e 50 vizinhos mais próximos. A rede RBF foi treinada com o método chamado SVD, portanto não possui ciclos. $A$ Tabela 6.2 apresenta resultados obtidos pela rede RBF. Apesar do resultado na fase de treinamento ser satisfatório, os resultados nas fases de validação e teste não foram bons. A rede não conseguiu uma boa generalização.

\begin{tabular}{||l|c|c|c||}
\hline RBF & TREINAMENTO & VALIDAÇÃO & TESTE \\
\hline Errado & 0,55 & 3,79 & 4,09 \\
\hline Certo & 90,62 & 76,30 & 79,40 \\
\hline Desconhecido & 8,83 & 19,90 & 16,51 \\
\hline
\end{tabular}

Tabela 6.2 - Resultado da rede RBF. 
A melhor rede MLP, treinada com o algoritmo Standard Backpropagation, é formada por 2 camadas intermediárias, com 30 neurônios na primeira camada e 10 neurônios na segunda. O número máximo de ciclos utilizados foi 10000 ciclos. A Tabela 6.3 apresenta os resultados obtidos pela rede em todas as fases. Os resultados foram satisfatórios.

\begin{tabular}{|l|c|c|c|}
\hline MLP & TREINAMENTO & VALIDAÇÃO & TESTE \\
\hline Errado & 1,26 & 8,53 & 10,38 \\
\hline Certo & 97,64 & 88,62 & 88,05 \\
\hline Desconhecido & 1,10 & 2,85 & 1,57 \\
\hline
\end{tabular}

Tabela 6.3 - Resultado da rede MLP.

Os resultados da rede MLP foram superiores aos resultados das redes RBF e Cascade Correlation. A desvantagem da rede MLP apresentada nesta base de dados foi o tempo de treinamento.

A seguir serão apresentados os resultados dos métodos de combinação de classificadores. Neste sistema de combinação as redes já apresentadas funcionam como classificadores individuais.

O método de Votação obteve um desempenho negativo na fase de teste, vide Tabela 6.4. O desempenho foi negativo por ter sido pior que o desempenho obtido pelas redes RBF e MLP. Isso aconteceu porque durante a fase de votação ocorreram vários erros coincidentes. Desta forma, o método de votação elegia várias vezes a classe errada para padrōes de teste.

\begin{tabular}{|l|c|c|c|}
\hline VOTAÇÃO & TREINAMENTO & VALIDAÇÃO & TESTE \\
\hline Errado & 10,56 & 12,48 & 8,49 \\
\hline Certo & 75,73 & 68,56 & 71,38 \\
\hline Desconhecido & 13,71 & 18,96 & 20,13 \\
\hline
\end{tabular}

Tabela 6.4 - Resultado do método combinação pela Votação. 
A Tabela 6.5 apresenta o desempenho obtido pelo método Soma Máxima. $O$ desempenho deste método foi mais que $2 \%$ melhor que o melhor desempenho dos classificadores. Isso ocorreu porque este método analisa se todos os classificadores estão convergindo para a uma única resposta, e acrescenta a convergência de cada classificador ao resultado flnal. Assim, pequenas tendências corretas, que antes eram irrelevantes na classlficação, somadas às tendências dos outros classificadores tomam-se relevantes na classificação.

\begin{tabular}{|l|c|c|c|}
\hline SOMA MÁXIMA & TREINAMENTO & VALIDAÇĀO & TESTE \\
\hline Errado & 5,83 & 13,43 & 9,75 \\
\hline Certo & 94,17 & 86,57 & 90,25 \\
\hline Desconhecido & 0,00 & 0,00 & 0,00 \\
\hline
\end{tabular}

Tabela 6.5 - Resultado do método combinaçăo pela Soma Máxima.

O resultado do método de combinação pela Média apresentado na Tabela 6.6 foi ruim. Este resultado sugere que a média das confiabilidades dos classificadores piorou o desempenho. A média piorou o desempenho porque diminuiu para alguns padrões a diferença de confiabilidade entre as classes. Desta forma, padrões que antes eram classificados corretamente por pequena margem de segurança, agora são classificados incorretamente.

\begin{tabular}{|l|c|c|c|}
\hline MÉDIA & TREINAMENTO & VALIDAÇÃO & TESTE \\
\hline Errado & 0,31 & 2,21 & 3,14 \\
\hline Certo & 65,80 & 63,51 & 68,08 \\
\hline Desconhecido & 33,89 & 34,28 & 28,78 \\
\hline
\end{tabular}

Tabela 6.6 - Resultado do método combinação pela Média. 
A Tabela 6.7 mostra os resultados obtidos pelo método Média Ponderada 321. Este método obteve resultados ruins. Isto ocorreu provavelmente pela média equiparar as respostas corretas e repostas erradas. O resultado desta equiparação foi muitos padrōes classificados como desconhecidos.

\begin{tabular}{|l|c|c|c|}
\hline MÉDIA PONDERADA 321 & TREINAMENTO & VALIDAÇÃO & TESTE \\
\hline Errado & 0,16 & 1,26 & 1,42 \\
\hline Certo & 47,12 & 47,86 & 53,14 \\
\hline Desconhecido & 52,72 & 50,87 & 45,44 \\
\hline
\end{tabular}

Tabela 6.7 - Resultado do método de combinação pela Média Ponderada 321.

A melhor rede de combinação MLP, treinada com o algoritmo Standard Backpropagation, é formada por 1 camada intermediária, com 8 neurônios. 0 número máximo de ciclos utilizados foi 1000. Neste método os classificadores funcionam como filtros. Como para esta base de dados, os dados foram bem filtrados pelos classificadores, o aprendizado para a rede de combinação foi facilitado. Por isso este método de combinação obteve um melhor desempenho em relação aos classificadores individuais.

\begin{tabular}{|l|c|c|c|}
\hline COMBINAÇĀo MLP & TREINAMENTO & VALIDAÇÃo & TESTE \\
\hline Errado & 0,48 & 7,11 & 7,23 \\
\hline Certo & 99,05 & 89,57 & 89,15 \\
\hline Desconhecido & 0,47 & 3,32 & 3,61 \\
\hline
\end{tabular}

Tabela 6.8 - Resultado do método de combinação pela rede MLP.

O último experimento utilizou a rede RBF para realizar a combinação. Esta rede RBF ficou com 50 unidades intermediárias e 20 vizinhos mais próximos. A rede de combinação RBF foi treinada com o método SVD. Neste caso os dados também foram bem filtrados, mas a rede RBF não obteve um desempenho melhor do que aquele 
obtidos pelos classificadores individuais. Talvez tenha ocorrido um overfitting no treinamento, provavelmente pelo treinamento ser realizado pelo método SVD.

\begin{tabular}{|l|c|c|c|}
\hline COMBINAÇĀO RBF & TREINAMENTO & VALIDAÇĀO & TESTE \\
\hline Errado & 0,55 & 9,32 & 10,53 \\
\hline Certo & 99,13 & 88,00 & 86,48 \\
\hline Desconhecido & 0,32 & 2,69 & 2,99 \\
\hline
\end{tabular}

Tabela 6.9 - Resultado do método de combinaçăo pela rede RBF.

Analisando comparativamente os resultados apresentados na Tabela 6.10, verificase uma vantagem de desempenho de mais de $2 \%$ de acerto do método de combinação proposto sobre o desempenho da melhor Rede Neural. Além disso, o método proposto obteve um desempenho de mais de $1 \%$ sobre o melhor desempenho dos outros métodos de classificação. Desta forma, a proposta deste método justifica-se diante do seu desempenho para esta base de dados.

\begin{tabular}{||l|c|}
\hline \multicolumn{1}{|c|}{ MÉTODOS } & TAXA DE ACERTO \\
\hline Combinação pela Soma Máxima & 90,25 \\
\hline Combinação pela rede MLP & 89,15 \\
\hline Rede MLP & 88,05 \\
\hline Combinação pela rede RBF & 86,48 \\
\hline Rede RBF & 79,40 \\
\hline Combinação pela Votação & 71,38 \\
\hline Rede Cascade Correlation & 70,28 \\
\hline Combinação pela Média & 68,08 \\
\hline Combinação pela Média Ponderada 321 & 53,14 \\
\hline
\end{tabular}

Tabela 6.10 - Comparação entre o desempenho dos métodos de combinação na fase de teste. 
A seguir serão apresentados os resultados dos experimentos realizados com os dados da Marinha Americana.

\section{4 - Experimentos com dados da Marinha Americana}

Esta base de dados foi cedida pela Marinha Americana. Esta base de dados é formada pela extração de 11 características de navios. Ela foi obtida de oito tipos de navios, assim a base de dados possui 8 classes de classificação. $O$ conjunto de dados possui 2545 padrões. Todas as redes utilizadas nessa base de dados possuiam 11 entradas e 8 saídas. A Tabela 6.11 ilustra os resultados obtidos pela rede Cascade Correlation. A rede Cascade Correlation, após o treinamento ficou com 100 unidades intermediárias. O número máximo de ciclos utilizados foi 2000.

\begin{tabular}{|l|c|c|c||}
\hline CASCADE CORRELATION & TREINAMENTO & VALIDAÇĀo & TESTE \\
\hline Errado & 2,02 & 2,25 & 2,83 \\
\hline Certo & 75,76 & 73,37 & 72,11 \\
\hline Desconhecido & 22,23 & 24,37 & 25,05 \\
\hline
\end{tabular}

Tabela 6.11 - Resultado da rede Cascade Correlation.

A rede RBF ficou com 180 unidades intermediárias e 50 vizinhos mais próximos. Esta rede RBF também foi treinada com o método SVD. Os resultados obtidos para a rede RBF estão ilustrados na Tabela 6.12.

\begin{tabular}{|l|c|c|c|}
\hline RBF & TREINAMENTO & VALIDAÇÃO & TESTE \\
\hline Errado & 0,78 & 1,36 & 1,73 \\
\hline Certo & 89,79 & 83,75 & 82,76 \\
\hline Desconhecido & 9,43 & 14,88 & 15,51 \\
\hline
\end{tabular}

Tabela 6.12 - Resultado da rede RBF. 
A melhor rede MLP, treinada com o algoritmo Standard Backpropagation, é formada por 2 camadas intermediárias, com 12 neurônios na primeira e 10 neurônios na segunda camada intermediária. O número máximo de ciclos utilizados foi 10000 .

\begin{tabular}{|l|c|c|c|}
\hline MLP & TREINAMENTO & VALIDAÇÃo & TESTE \\
\hline Errado & 1,52 & 3,72 & 6,03 \\
\hline Certo & 97,20 & 93,19 & 90,93 \\
\hline Desconhecido & 1,28 & 3,09 & 3,04 \\
\hline
\end{tabular}

Tabela 6.13 - Resultado da rede MLP.

A seguir serão apresentados os resultados obtidos pelos métodos de combinação de classificadores. As Redes Neurais apresentadas são utilizadas como classificadores nos métodos de combinação.

O resultado do método de Votação, apresentado na Tabela 6.14 , foi superior ao dos classificadores individuais. Isto sugere que a interseção do espaço de classificação correta de pelo menos dois classificadores é maior que o espaço de classificação de cada classificador. Isto significa que os classificadores estão se complementando nesta base de dados.

\begin{tabular}{|l|c|c|c|}
\hline VOTAÇÃO & TREINAMENTO & VALIDAÇÃO & TESTE \\
\hline Errado & 1,89 & 3,77 & 4,87 \\
\hline Certo & 96,00 & 92,71 & 91,41 \\
\hline Desconhecido & 2,12 & 3,51 & 3,72 \\
\hline
\end{tabular}

Tabela 6.14 - Resultado do método de combinação pela Votaçăo.

O método proposto, Soma Máxima, mais uma vez produziu bons resultados, vide Tabela 6.15. Isto ocorreu, porque o método avalia a confiança de cada rede em uma resposta para cada padrão e determina a resposta final em função da credibilidade. Assim a classe com maior confiabilidade é indicada para o padrão desconhecido. 


\begin{tabular}{|l|c|c|c|}
\hline SOMA MÁXIMA & TREINAMENTO & VALIDAÇĀO & TESTE \\
\hline Errado & 2,07 & 4,30 & 5,24 \\
\hline Certo & 97,93 & 95,70 & 94,76 \\
\hline Desconhecido & 0,00 & 0,00 & 0,00 \\
\hline
\end{tabular}

Tabela 6.15 - Resultado do método de combinaçäo Soma Máxima.

O método Média das saídas dos classificadores produziu o resultado esperado nesta base de dados, vide Tabela 6.16. O resultado deste método foi melhor que a média dos resultados dos classificadores.

\begin{tabular}{|l|c|c|c|}
\hline MÉDIA & TREINAMENTO & VALIDAÇĀO & TESTE \\
\hline Errado & 0,89 & 1,78 & 1,83 \\
\hline Certo & 92,41 & 87,89 & 86,63 \\
\hline Desconhecido & 6,71 & 10,32 & 11,53 \\
\hline
\end{tabular}

Tabela 6.16 - Resultado do método de combinação pela Média.

No método Média Ponderada 321 ocorreu o mesmo fato observado com o método anterior. O resultado apresentado na Tabela 6.17 foi melhor porque a rede de melhor desempenho possui o maior peso. Para esta base de dados a ponderação funcionou bem.

\begin{tabular}{|l|c|c|c|}
\hline MÉDIA PONDERADA 321 & TREINAMENTO & VALIDAÇĀO & TESTE \\
\hline Errado & 1,10 & 2,25 & 3,35 \\
\hline Certo & 96,70 & 92,24 & 90,35 \\
\hline Desconhecido & 2,20 & 5,51 & 6,29 \\
\hline
\end{tabular}

Tabela 6.17 - Resultado do método de combinação pela Média Ponderada 321. 
A melhor rede de combinação MLP, treinada com 0 algoritmo Standard Backpropagation, é formada por 1 camada intermediária, com 16 neurônios. $O$ número máximo de ciclos utilizados foi 1000 ciclos. Nesta base de dados os dados foram bem filtrados pelos classificadores individuais, o aprendizado para a rede de combinação foi facilitado. Por isso este método de combinação obteve uma boa performance.

\begin{tabular}{|l|c|c|c|}
\hline COMBINAÇÃO MLP & TREINAMENTO & VALIDAÇĀO & TESTE \\
\hline Errado & 0,65 & 2,57 & 3,93 \\
\hline Certo & 98,66 & 94,23 & 92,98 \\
\hline Desconhecido & 0,68 & 3,19 & 3,09 \\
\hline
\end{tabular}

Tabela 6.18 - Resultado do método de combinação pela rede MLP.

A rede de combinação RBF ficou com 160 unidades intermediárias e 60 vizinhos mais próximos. A rede de combinação RBF foi treinada com o método SVD. Os resultados estão apresentados na Tabela 6.19. A rede RBF não obteve um desempenho na fase de teste melhor que os classificadores, apesar de obter um bom desempenho no treinamento. $O$ bom desempenho da fase de treinamento se deve ao fato do método de combinação possuir retreinamento.

\begin{tabular}{||l|c|c|c|}
\hline COMBINAÇÃo RBF & TREINAMENTO & VALIDAÇĀO & TESTE \\
\hline Errado & 0,42 & 2,04 & 3,62 \\
\hline Certo & 98,30 & 92,82 & 90,93 \\
\hline Desconhecido & 1,28 & 5,14 & 5,45 \\
\hline
\end{tabular}

Tabela 6.19 - Resultado do método de combinação pela rede RBF.

$\mathrm{Na}$ Tabela 6.20 verifica-se uma vantagem do desempenho de quase $4 \%$ de acerto do método de combinação proposto sobre o desempenho do melhor classificador individual. 


\begin{tabular}{|l|c|}
\hline \multicolumn{1}{|c|}{ MÉTODOS } & TAXA DE ACERTO \\
\hline Combinação pela Soma Máxima & 94,76 \\
\hline Combinação pela rede MLP & 92,98 \\
\hline Combinação pela Votação & 91,41 \\
\hline Combinação pela rede RBF & 90,93 \\
\hline Rede MLP & 90,93 \\
\hline Combinação pela Média Ponderada 321 & 90,35 \\
\hline Combinação pela Média & 86,63 \\
\hline Rede RBF & 82,76 \\
\hline Cascade Correlation & 72,11 \\
\hline
\end{tabular}

Tabela 6.20 - Comparação entre o desempenho dos métodos de combinação na fase de teste.

O método proposto obteve também um desempenho de quase $2 \%$ melhor sobre o melhor desempenho dos outros métodos de classificação. Esses bons resultados confirmam as vantagens deste método apresentadas no capítulo de Combinação de Classificadores. A seguir será apresentado os experimentos realizados com a base de dados proveniente da Marinha do Brasil.

\section{5 - Experimentos com dados da Marinha Brasileira}

Essa base de dados é formada por 1024 pixels representando imagens de navios. Quatro tipos de navios foram estudos, assim a base de dados possui 4 classes de classificação. Esta base foi fornecida pela Marinha Brasileira. O conjunto de dados possui 800 padrões.

Todas as redes utilizadas como classificadores nesta base de dados possuiam 1024 entradas e 4 saídas. A rede Cascade Correlation após o treinamento ficou com 40 neurônios intermediários. O número máximo de ciclos de treinamento utilizado foi 50 . 
A Tabela 6.21 apresenta os resultados da rede Cascade Correlation. Note que, apesar da pequena quantidade de ciclos utilizados no treinamento, a rede obteve $100 \%$ de acerto na fase de aprendizado.

\begin{tabular}{|l|c|c|c|}
\hline CASCADE CORRELATION & TREINAMENTO & VALIDAÇÃo & TESTE \\
\hline Errado & 0,00 & 1,7 & 2,0 \\
\hline Certo & 100,0 & 90,2 & 88,5 \\
\hline Desconhecido & 0,00 & 8,2 & 9,5 \\
\hline
\end{tabular}

Tabela 6.21 - Resultado da rede Cascade Correlation.

A rede RBF ficou com 70 unidades intermediárias e 15 vizinhos mais próximos. A Tabela 6.22 apresentada os bons resuitados obtidos pela rede RBF. Estes resultados indica que a rede RBF obteve um bom desempenho.

\begin{tabular}{|l|c|c|c|}
\hline RBF & TREINAMENTO & VALIDAÇÃO & TESTE \\
\hline Errado & 0,2 & 0,3 & 0,00 \\
\hline Certo & 97,6 & 96,2 & 94,8 \\
\hline Desconhecido & 2,3 & 3,5 & 5,2 \\
\hline
\end{tabular}

Tabela 6.22 - Resultado da rede RBF.

A melhor rede MLP, treinada com o algoritmo Standard Backpropagation, é formado por 2 camadas intermediárias, com 50 neurônios na primeira e 20 neurônios na segunda camada intermediária. O número máximo de ciclos na fase de treinamento foi 1000. A Tabela 6.23 apresenta o desempenho da rede MLP nesta base de dados. Como pode ser visto nestes resultados, a rede MLP apresentou o melhor desempenho entre os classificadores individuais. 


\begin{tabular}{|l|c|c|c|}
\hline MLP & TREINAMENTO & VALIDAÇĀO & TESTE \\
\hline Errado & 0,00 & 0,7 & 0,5 \\
\hline Certo & 99,7 & 98,0 & 98,3 \\
\hline Desconhecido & 0,3 & 1,3 & 1,2 \\
\hline
\end{tabular}

Tabela 6.23 - Resultado da rede MLP.

Deve ser observado que, apesar da rede Cascade Correlation obter o melhor desempenho na fase de treinamento, ela obteve o pior desempenho na fase de teste. Isto ocorreu pela falta de generalização da rede para esta base de dados. Novamente a rede MLP obteve o melhor desempenho na fase de teste. A rede RBF também obteve bons resultados com esta base de dados. Se a comparação das redes fosse feita levando em consideração o tempo de treinamento, a rede RBF seria a melhor alternativa.

A seguir serão apresentados os resultados obtidos pelos métodos de combinação.

O resultado do método de Votação, apresentado na Tabela 6.24 , inferior ao obtido pela rede MLP, mostra que a interseção do espaço de classificação correta entre pelo menos dois resultados é menor que o espaço de cada uma das redes. Isto significa que estão ocorrendo erros coincidentes neste problema.

\begin{tabular}{|l|c|c|c|}
\hline VOTAÇĀo & TREINAMENTO & VALIDAÇÄO & TESTE \\
\hline Errado & 0,2 & 0,8 & 0,8 \\
\hline Certo & 99,8 & 98,3 & 97,3 \\
\hline Desconhecido & 0,00 & 0,8 & 1,8 \\
\hline
\end{tabular}

Tabela 6.24 - Resultado do método de combinação pela Votação.

A Tabela 6.25 apresenta os resultados do método Soma Máxima. Mais uma vez deve ser observado que este método apresentou o melhor resultado. Apesar do método não possuir retreinamento, ele obteve $100 \%$ de aprendizado na fase de treinamento. Além disso, o método obteve o melhor desempenho na fase de teste. 


\begin{tabular}{|l|c|c|c|}
\hline SOMA MÁXIMA & TREINAMENTO & VALIDAÇÃO & TESTE \\
\hline Errado & 0,00 & 1,3 & 1,3 \\
\hline Certo & 100,0 & 98,7 & 98,7 \\
\hline Desconhecido & 0,00 & 0,00 & 0,00 \\
\hline
\end{tabular}

Tabela 6.25 - Resultado do método de combinação Soma Máxima.

O método Média das saídas dos classificadores produziu o resultado esperado nesta base de dados. O resultado deste método, apresentado na Tabela 6.26 , foi melhor que a média dos resultados apresentados pelas Redes Neurais.

\begin{tabular}{|l|c|c|c|}
\hline MÉDIA & TREINAMENTO & VALIDAÇÃo & TESTE \\
\hline Errado & 0,00 & 0,3 & 0,2 \\
\hline Certo & 99,8 & 95,5 & 95,0 \\
\hline Desconhecido & 0,2 & 4,2 & 4,8 \\
\hline
\end{tabular}

Tabela 6.26 - Resultado do método de combinação pela Média.

Para o método Média Ponderada 321 ocorreu o esperado. O resultado apresentado na Tabela 6.27 é melhor que o resultado da apresentado na Tabela 6.26, pois a rede de melhor desempenho possui, neste método, maior peso na média.

\begin{tabular}{|l|c|c|c|}
\hline MÉDIA PONDERADA 321 & TREINAMENTO & VALIDAÇĀO & TESTE \\
\hline Errado & 0,00 & 0,5 & 0,2 \\
\hline Certo & 99,7 & 97,8 & 98,0 \\
\hline Desconhecido & 0,3 & 1,7 & 1,8 \\
\hline
\end{tabular}

Tabela 6.27 - Resultado do mátodo de combinação pela Média Ponderada 321. 
A melhor rede de combinação MLP, treinada com o algoritmo Standard Backpropagation, é formada por 1 camada intermediária, com 6 neurônios. $O$ número máximo de ciclos utilizados foi 1000 . Nesta base de dados a filtragem dos dados não facilitou muito a classificação, por isso o método de combinação pela rede MLP obteve um desempenho inferior ao melhor desempenho dos classificadores individuais.

\begin{tabular}{|l|c|c|c|}
\hline COMBINAÇÃo MLP & TREINAMENTO & VALIDAÇÃo & TESTE \\
\hline Errado & 0,00 & 1,0 & 0,8 \\
\hline Certo & 100,0 & 98,2 & 97,8 \\
\hline Desconhecido & 0,00 & 0,8 & 1,3 \\
\hline
\end{tabular}

Tabela 6.28 - Resultado do método de combinação pela rede MLP.

A Tabela 6.29 apresenta os resultados obtidos pela combinação feita pela rede RBF. Esta rede RBF ficou com 50 unidades intermediárias e 40 vizinhos mais próximos. Este método obteve $100 \%$ de aprendizado na fase de treinamento, isso ocorreu porque este método utiliza retreinamento. Note que os resultados deste método na fase de teste não foram muito bons, porque a filtragem dos dados feita pelos classificadores não funcionou como desejado para esta base de dados.

\begin{tabular}{|l|c|c|c|}
\hline COMBINAÇÃo RBF & TREINAMENTO & VALIDAÇÃO & TESTE \\
\hline Errado & 0,00 & 0,3 & 0,8 \\
\hline Certo & 100,0 & 95,8 & 96,3 \\
\hline Desconhecido & 0,00 & 3,8 & 2,8 \\
\hline
\end{tabular}

Tabela 6.29 - Resultado do método de combinaçăo pela rede RBF.

A filtragem de dados feita pelos classificadores não funcionou nesta base de dados provavelmente pelo grande número de entradas. Nesta base cada classificador possui 1024 entrada. Quanto maior o número de entrada, maior a possibilidade de entrar ruídos na classificação. 
A Tabela 6.30 apresenta uma comparação de desempenho na fase de teste entre os métodos de combinação utilizados nesta base de dados. Nesta comparação, o método de combinação pela Soma Máxima continua produzindo os melhores resultados. Um fato importante aconteceu nesta base de dados. Este fato foi que apesar do método Soma Máxima não utilizar retreinamento, obteve um ótimo desempenho na fase de treinamento.

\begin{tabular}{|l|l|}
\hline \multicolumn{1}{|c|}{ MÉTODOS } & TAXA DE ACERTO \\
\hline Combinação pela Soma Máxima & 98,7 \\
\hline Rede MLP & 98,3 \\
\hline Combinação pela Média Ponderada 321 & 98,0 \\
\hline Combinação pela Rede MLP & 97,8 \\
\hline Combinação pela Votação & 97,3 \\
\hline Combinação pela Rede RBF & 96,3 \\
\hline Combinação pela Média & 95,0 \\
\hline Rede RBF & 94,8 \\
\hline Rede Cascade Correlation & 88,5 \\
\hline
\end{tabular}

Tabela 6.30 - Comparação entre o desempenho dos métodos de combinação na fase de teste.

A seguir será apresentada a conclusão deste capítulo.

\section{6 - Conclusão}

Neste capítulo foram analisados os desempenhos obtidos por três classificadores: Cascade Correlation, Radial Basis Function e Multi-Layer Perceptron; e seis métodos de combinação: Votação, Soma Máxima, Média, Média Ponderada 321 e por Redes Neurais (MLP e RBF). Para tal, foram utilizados três bases de dados. As Redes Neurais apresentaram bons resultados, porém o mais importante é a diferença de desempenho entre as redes e os métodos de combinação. 
O método de Combinação pela Votação apresentou bons resultados quando os classificadores concordavam, ou seja, quando pelo menos duas classificações eram corretas para os mesmos padrões.

O método proposto, Soma Máxima, superou as expectativas. Esse método obteve um desempenho em todas as bases de dados tão bom ou superior a todos os outros métodos aplicados nesta dissertação. Além disso, apesar deste método não utilizar retreinamento, o que o deixa mais rápido, produziu também bons resultados na fase de treinamento.

O método Combinação pela Média das saídas dos classificadores não apresentou bons resultados. Isto acontece, provavelmente, porque o método equipara tendências corretas e tendências erradas quando calcula a média. Nesta equiparação, erros grande são somados a acertos pequenos, assim na média o erro prevalece. Nos casos com acerto por pequena margem de segurança, com a equiparação, as saídas tomamse desconhecidas. O mesmo acontece para o método de Combinação pela Média Ponderada 321.

Nos método de Combinação pela Rede MLP, os classificadores funcionam com filtros dos dados. Quando os dados possuem ruídos que são eliminados pelos classificadores, este método obtém bons resultados. Quando os ruídos não são eliminados, os resultados são apenas razoáveis. O método combinação pela rede RBF se enquadra no mesmo problema, apesar de apresentar um desempenho inferior ao da combinação pela rede MLP.

Pelos experimentos realizados, a combinação de classificadores confirmou as expectativas. Além de estabilizar as respostas dos classificadores, em vários casos produziu um desempenho melhor que aqueles obtidos pelos classificadores individuais. $O$ aumento de tempo no processamento foi compensado com a melhoria da performance. No próximo capítulo será apresentada a conclusão desta dissertação. 


\section{CONCLUSÃO E TRABALHOS FUTUROS}

\section{1 - Conclusão}

Os sistemas de Reconhecimento de Padrões necessitam de avanços, pois são utilizados nas mais variadas aplicações. Para isso, novas técnicas estão sendo desenvolvidas para o aprimoramento do desempenho desses sistemas. Uma técnica que pode ser aliada ao Reconhecimento de Padrões é a de Combinação de Classificadores. Neste trabalho, problemas são tratados utilizando Combinação de Classificadores para o Reconhecimento de Padrões.

A abordagem de Reconhecimento de Padrões adotada neste trabalho foi a conexionista. Uma abordagem mista, com classificadores estatísticos e simbólicos, também foi analisada. A decisão sobre quais classificadores seriam combinados foi baseada nos seguintes itens; o desempenho apresentado pelas Redes Neurais, a facilidade de aplicar uma Rede Neural em um sistema de combinação, as características das Redes Neurais.

Definida a abordagem adotada, a próxima decisão estava relacionada a quais e quantas Redes Neurais deveriam ser utilizadas. Não existem respostas diretas a estas questões, o que existe são sugestões para a obtenção de um melhor desempenho. Uma sugestão importante sobre quais redes utilizar é a escolha de redes com características diferentes. Esta sugestão foi utilizada e por isso foram escolhidas as redes: Cascade Correlation, Multi-Layer Percetron e Radial Basis Function.

Apenas três Redes Neurais foram utilizadas para a combinação, porque este número, por não ser muito grande, evita a demora excessivamente do processo de treinamento. 
Vários métodos de combinação foram utilizados. Permitindo uma comparação entre vários métodos de combinação. Além disso, um método de combinação foi proposto. $A$ comparação deste método com outros métodos foi de grande importância.

O método proposto tem por objetivo melhorar o desempenho de um sistema de combinação para Reconhecimento de Padrões. Nesta nova forma, a combinação também considera a representação das classes de padrões para a classificação, e não somente a classe selecionada pelos classificadores. A combinação pode ser um processo muito mais abrangente do que apenas analisar quantas vezes uma classe foi sugerida pelos classificadores.

Para a comparação dos métodos, três bases de dados foram utilizadas. A primeira dela contém dados de imagens de silhuetas de veículos. A segunda é uma base de dados de imagens de navios da Marinha Americana. A terceira é a base de dados de imagens de navios fomecida pela Marinha Brasileira. A base de dados da Marinha Brasileira está sendo utilizada no projeto SAPRI, cuja dissertação é parte integrante.

Os bons resultados dos métodos de combinação mostraram a viabilidade de aplicações dos mesmos em diferentes problemas. Além disso, os métodos de combinação sem retreinamento, como é o caso do método proposto, apresentaram um bom desempenho também em relação ao tempo.

O desempenho do método proposto superou as expectativas. Este método, além de realizar o processo de combinação rapidamente, apresentou resultados muito bons. Desta forma, as justificativas da proposta do método estão no desempenho apresentado por ele, na nova abordagem do problema de combinação e no tempo para a realização da combinação.

\section{2 - Trabalhos Futuros}

A partir dos resultados deste trabalho, várias extensões podem ser propostas. A primeira é referente a avaliar o desempenho da combinação de diferentes tipos de classificadores. Uma combinação interessante seria utilizar classificadores estatísticos, simbólicos e conexionistas; cooperando para a resolução de um mesmo problema.

Uma outra aplicação seria analisar comparativamente a combinação com diferentes números de classificadores na mesma combinação. De forma a obter um número 
razoável de classificadores em função do tempo e do desempenho obtido pelas combinações. Um sugestão seria comparar combinações utilizando três, cinco e sete classificadores.

A próxima extensão seria analisar matematicamente as implicações do método proposto, Soma Máxima, nas respostas fornecidas. Esta análise deveria medir o grau de confiança de suas respostas e medir o tempo de combinação. Além disso, deveria avaliar como ficariam as funções modeladas pelos classificadores após a combinação.

Uma aplicação de grande interesse seria utilizar técnicas de algoritmos genéticos para a otimização dos classificadores e das redes de combinação. Assim, os classificadores seriam ótimos e estariam cooperando na resolução do mesmo problema.

Além dessas, várias outras aplicações poderiam ser sugeridas, pois a Combinação de Classificadores é uma área que tende a obter um grande crescimento nos próximos anos. 


\section{REFERÊNCIAS BIBLIOGRÁFIACAS}

[ABBA, 92] ABBAS, H.M. and Fahmy, M.M., "A Neural Model for Adaptive Karhunen-Loeve Transform (KLT)", IEEE International Joint Conference on Neural Networks, v. 2, p. 975-980, Baltimore, MD, 1992.

[Allen, 95] Waxman, Allen M., Sibert, M. C., Gove, A., Fay, D. A., Bernardon, A. M., Lazott, C., Steele, W. R. and Cunningham, R. K., "Neural Processing of Targets in Visible, Multispectral IR and SAR Imagery", Neural Networks, v. 8, 1995.

[Barnett, 81] Barnett, J. A., "Computational Methods for a Mathematical Theory of Evidence.", Artigos do IFCAI, 1981.

[Beale, 94] Beale, R. and Jackson T., "Neural Computing: An Introduction", IOP Publising Ltd, 1994.

[Bernardon, 95] Bemardon, A. M. and Carrick, J. E., "A Neural System for Automatic Target Learning and Recognition Applied to Bare and Camouflaged SAR Targets", Neural Networks, v. 8, n. $7 / 8$, p. $1103-1108,1995$.

[Bird, 95] Bird, S. D. and Kasper, G. M., "Problem Formalization Techniques for Collaborative Systems", IEEE Transaction on Systems, Man, and Cybernetics, v. 25, n. 2, p. 231-242, 1995.

[Bishop, 96] Bishop, C. M., "Neural Networks for Pattern Recognition", Oxford University Press, 1996. 
[Chuanyi, 97] Ji, Chuanyi and Ma, S., "Combinations of Weak Classifiers", IEEE Transactions on Neural Networks, v. 8, n. 1, p. 32-42, 1997.

[Fahlman, 90] Fahlman, S. E. and Lebiere, C., "The Cascade-Correlation Learning Architeture", in D. S. Touretzky (ed.), Advances in Neural Information Processing Systems 2 , Morgan Kaufmann, 1990.

[Grossberg, 82] Grossberg, S., "Studies of Mind and Brain", Boston, MA, Reidel, 1982.

[Grossberg, 95] Grossberg, S., Hawkins, H. and Waxman, A., "Introduction: 1995 Special Issue Automatic Target Recognition", Neural Networks, v. 8, 1995.

[Grossberg, 95] Grossberg, S., Mingolla, E. and Williamson, J., "Synthetic Aperture Radar Processing by a Multiple Scale Neural System For Boundary and Surface Representation", Neural Networks, v. 8, n. 7/8, 1995.

[Haykin, 91] Haykin, S. and Deng, C., "Classification of Radar Clutter Using Neural Nerworks", IEEE Transactions on Neural Networks, v. 2, n. 6, p. 589-600, November, 1991.

[Haykin, 94] Haykin, S., "Neural Networks: A Comprehensive Foundation", Macmillan College Publishing Company, New York, 1994.

[Ho, 94] Ho, T. K., Hull, J. J. and Srihari, S. N., "Decision Combination in Multiple Classifier Systems", IEEE Transaction on Pattern Analysis Machine Intelligence, v. 16, n. 1, p. 66-75, 1994.

[Hush, 93] Hush, D. R. and Horne, B. G., "Progress in Supervised Neural Networks: What's New Since Lippmann?", IEEE Signal Processing Magazine, p. 8-39, January, 1993. 
[Jacobs, 97] Jacobs, R. A, Peng, F. and Tanner, M. A., "A Bayesian Approach to Model Selection in Hierarchical Mixture-of-Experts Architetures", Neural Networks, v. 10, n. 2, p. 231241, 1997.

[Jordan, 94] Jordan, M. I. and Jacobs, R. A., "Hierarchical Mixtures of Experts and the EM Algorithm", Neural Computation, v. 6, n. 1, p. 181-214, 1994.

[Jordan, 95] Jordan, M. I. and Xu, L., "Convergence Results for the EM Approach to Mixtures of Experts Architectures", Neural Networks, v. 8, n. 9, 1995.

[Knigth, 86] Knigth, J. C. and Leveson, N. G., "An Experimental Evaluation of Independence in Multiversion Programming.", IEEE Transaction on Software Engineering, SE-12, 1986.

[Koch, 95] Koch, M. W., Moya, M. M., Hostetler, L. D. and Fogler, R. J., "Cueing, Feature Discovery, and One-Class Learning for Synthetic Aperture Radar Automatic Target Recognition", Neural Networks, v. 8, n. 7/8, p. 1081-1102, 1995.

[Kohonen, 82] Kohonen, T., "Self-organized Formation of Topologically Correct Feature Maps", Biological Cybernetics, v. 43, p. 59-69, 1982.

[Llinás, 89] Llinás, R. R., "The Biology of the Brain - From Neurons to Networks", W.H. Freeman and Company, 1989.

[Lu, 96] Lu, Y., "Knowledge Integrations in a Multiple Classifier System", Applied Inteligence, v. 6, n. 1, p. 75-86, 1996.

[McCormack, 97] McCormack, C., "Adaptation of Learning Rule Prarameters Using a Meta Neural Networks", Connection Science, v. 9, n. 1, p. 123-136, 1997. 
[McCullock, 43] McCullock, W. S. and Pitts, W. H., "A Logical Calculus of Ideas Immanent in Nervous Activity", Bull Math Biophys, p. 115-133, 1943.

[Minsky, 69] Minsky, M. and Papert, S.A., "Perceptrons", MIT Press, 1969.

[Moody, 95], Moody, J., Abu-Mostafa, Y. and Weigend, A., "Trading with Committes: A Comparative Study", Neural Networks in the Capital Markets, 1995.

[Nasrabadi,97] Nasrabadi, N. M., "Automatic Target Recognition Using Artificial Neural Networks", SPEl's 11th Annual International Symposium on AeroSense, 20-25 April 1997.

[Nilsson, 65] Nilsson, N. J., "Learning Machines: Foundations of Trainable Pattern-Classifying Systems", NY, McGraw Hill, 1965.

[Park, 94] Park, Y., "A Comparison of Neural Net Classifiers and Linear Tree Classifiers: Their Similarities and Differences", Pattern Recognition, v. 27, n. 11, p. 1493-1503, 1994.

[Parker, 85] Parker, D.B., "Learning-Logic: Casting the Cortex of Human Brain in Silicon", Technical Report TR-47, Center for Computational Research in Economics and Management Science, MIT, Cambridge, MA, 1985.

[Poggio, 90] Poggio, T. and Girosi, F., "Networks for Aproximation and Learning". Proceedings of the IEEE, v. 78, p. 1481-1497, 1990.

[Press, 88] Press, W.H., Flannery, B.P., Teukolsky, S.A. and Vetterling, W.T., "Numerical Recipies in C", Cambridge University Press, 1988.

[Rauber, 97] Rauber, T. W., "Pattern Recognition", XVII Congress of the Brazilian Computer Science Society, Brasilia, Brasil, 1997. 
[Ripley, 96] Ripley, B. D., "Pattern Recognition via Neural Networks", 1996.

[Rogers, 95] Rogers, S. K., Colombi, J. M., Martin, C. E., Gainey, J. C., Fielding, K. H., Burns, T. J., Ruck, D. W., Kabrisky, M. and Oxley, M. "Neural Networks for Automatic Target Recognition", Neural Networks, v. 8, 1995.

[Rumelhart, 85] Rumelhart, D. E. and Zipser, D., "Feature Discovery by Competitive Learning", Cognitive Science, v. 9, p. 75-112, 1985.

[Rumelhart, 86] Rumelhart, D. E., Hinton, G. E. and Williams R. J., "Learning Internal Representation by Error Propagation", Parallel Distributed Processing, p. 318-362, MIT Press, 1986.

[Sharkey, 96] Sharkey, A. J. C., "On Combining Artificial Neural Nets", Connection Science, v. 8 , n. 3 e 4, p. 299-313, 1996.

[Sharkey, 97] Sharkey, A. J. C., "Modularity, Combining and Artificial Neural Nets", Connection Science, v. 9, n. 1, p. 3-10, 1997.

[Smith, 96] Smith, M., "Neural Networks for Statistical Modeling", International Thomson Computer Press, 1996.

[Vasconcelos, 95], Vasconcelos, G. C., "Redes Neurais e Reconhecimento de Padrões", ॥ Simpósio Brasileiro de Redes Neurais - Tutorial 2, 1995.

[Werbos, 74] Werbos, P. J., "Beyond Regression: New Tools for Prediction and Analysis in the Behavioral Sciences", PhD. Thesis, Harvard University, Cambridge, MA, 1974. 
[Xu, 92] Xu, L., Krzyzak, A. and Suen, C. Y., "Methods of Combining Multiple Classifiers and their Application to Handwriting Recognition", IEEE Transaction "Systems, Man, and, Cybernetics, v. 22, n. 3, p. 418- 435, 1992. 